\title{
Localised corrosion assessement of crambe-oil-based polyurethane coatings applied on the ASTM 1200 aluminum alloy
}

\author{
J.V. Nardeli ${ }^{a}$, D.V. Snihirova ${ }^{\text {b }}$, C.S. Fugivara ${ }^{a}$, M.F. Montemor ${ }^{\text {b }}$, E.R.P. Pinto ${ }^{\text {a }}$, \\ Y. Messaddecq ${ }^{\mathrm{a}}$, A.V. Benedetti ${ }^{\mathrm{a}, *}$ \\ a Departamento de Físico-Química, Instituto de Química, Universidade Estadual Paulista, UNESP, Araraquara, SP 14801-970, Brazil \\ ${ }^{\mathrm{b}}$ CQE - DEQ Instituto superior Técnico, Universidade de Lisboa, Av. Rovisco Pais, 1049-001 Lisboa, Portugal
}

\section{A R T I C L E I N F O}

\section{Article history:}

Received 6 February 2016

Received in revised form 18 May 2016

Accepted 19 May 2016

Available online 20 May 2016

\section{Keywords:}

Aluminium alloy

Organic coatings

Scratching electrode

EIS, SEM, Polymer coatings

\begin{abstract}
A B S T R A C T
Coatings composed of polyurethanes derived from polyesters of crambe oil and pre-polymer obtained from hexamethylene diisocyanate and castor oil were prepared (1:2 and 1:3, respectively) and applied on the Al alloy 1200 . The corrosion resistance of the coated panels was studied by linear polarization and conventional electrochemical impedance (EIS). The fraction of an active area of the substrate was around $0.017 \%$ and $0.013 \%$ for the $1: 2$ and $1: 3$ coatings, respectively. The performance of pristine samples was also studied by electrochemical impedance spectroscopy. An artificial scratch was performed on pristine samples and the local corrosion activity was studied by localized impedance spectroscopy (LEIS) and scanning vibrating electrode technique (SVET) in $\mathrm{NaCl}$ solutions. Filiform corrosion was observed for the panel coated with the modified polyester and pre-polymer $1: 3$ after $12 \mathrm{~h}$ of test. The scratched sample of modified polyester and pre-polymer 1:2 showed better performance in $\mathrm{NaCl}$ solution and the coating seems to present a self-healing response to the artificial damage.
\end{abstract}

@ 2016 Elsevier Ltd. All rights reserved.

\section{Introduction}

One of the most effective methods for the protection of a material and/or metallic materials against corrosion is the application of coatings [1]. To investigate the mechanism by which the coating protects the materials surface from initiation of corrosion, different localized techniques can be applied, such as the scanning vibrating electrode technique (SVET) [2,3], scanning reference electrode technique (SRET) [4,5], scanning electrochemical microscopy (SECM) [6,7], electrochemical microcell [8] and local electrochemical impedance spectroscopy (LEIS) [9-12].

The SVET vibrating probe detects the potential gradient generated on the surface as consequence of the redox processes and thus it is possible to measure both the anodic and cathodic ionic flux and therefore the corresponding current densities. The main advantage of using SVET is that the local corrosion activity can be studied without the need to polarize or perturb the sample. SVET has been used to study different localized corrosion processes [13,14] but provides little mechanistic information. On the other hand,

\footnotetext{
* Corresponding author.

E-mail addresses: benedeti@iq.unesp.br, avbenedetti@gmail.com (A.V. Benedetti).
}

localized electrochemical impedance spectroscopy (LEIS) by using a dual probe can detect the working electrode response due to an external bias perturbation. This provides relevant information related to the localized corrosion rates and mechanisms. LEIS has been applied extensively on uncoated (i.e. bare) substrates, however only recently it was applied to coated metals $[9,12,15,16]$. Being a local technique, LEIS can be used to characterize any intrinsic or extrinsic defect, which can alter the dielectric, electric, or ionic nature of the coating material/coating-substrate interface. Paired with SVET, both techniques provide relevant information on the corrosion behavior of coated samples.

Presently, energy and environment concerns are driving the search of corrosion protective coatings based on "green formulations". On the other hand, there is a need of developing more advanced coatings for conventional and to answer the requirements of several new Hi-Tech applications as emphasized by Montemor [17]. Thus, in this work natural-derived products are used to develop a coating formulation to protect $\mathrm{Al}$ and its alloys. The polyurethanes, materials derived from polyols and diisocyanates, due to their great versatility can be used as coatings for many applications, and become more attractive if polyols are synthesized from vegetable oils. In this way, coatings synthesized from vegetable oils [18-21] are interesting for many applications 
Table 1

Coatings composition: hydroxylated polyesters with pre-polymer H3 blended together oxygenated solvents. (For catalysts proportions see Supplementary material).

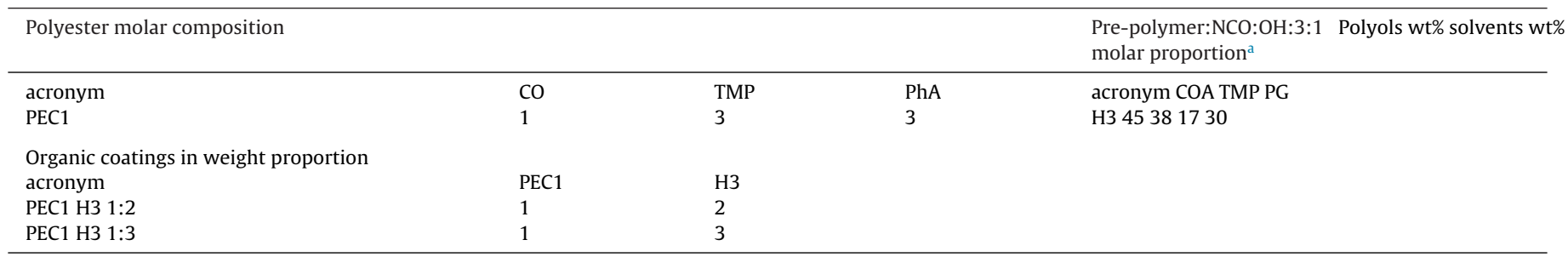

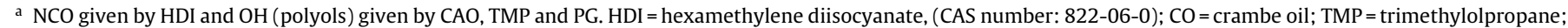
$\mathrm{CAO}=$ castor oil; $\mathrm{PhA}=$ phthalic anydride; $\mathrm{PG}=$ propyl glycol; solvents: ethyl acetate (10 wt\%), butyl acetate (10\%wt) and ethyl glycol acetate (10 wt\%).

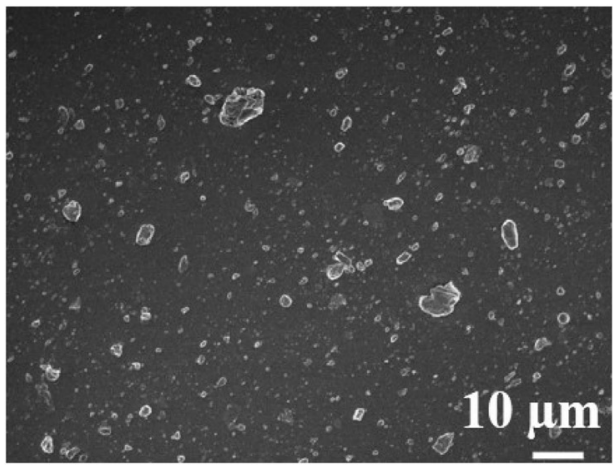

(A)

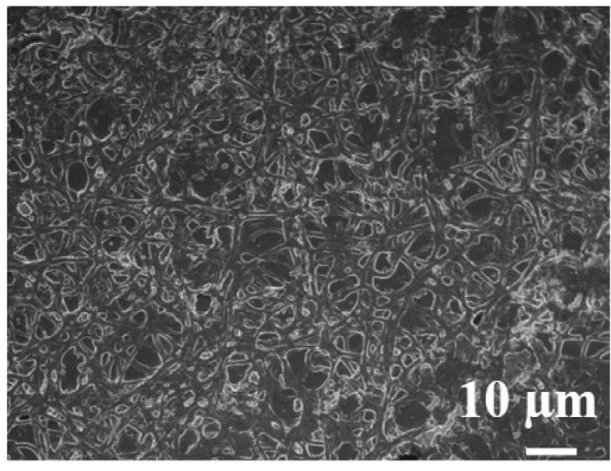

(B)

Fig. 1. Micrographs of the coatings surface: (A) PEC1 H3 1:2 and (B) PEC1 H3 1:3.

because they are renewable and inexpensive, constituting and alternative to raw materials derived from petroleum.

In a recent study [18], the electrochemical behavior of different polyurethane coatings derived from polyesters produced from crambe oil with (PEC1 or PEC2 derivatives) trimethylolpropane (TMP) and phthalic anhydride (PhA), and mixed with H3 (prepolymer: hexamethylene diisocyanate (HDI) with castor oil and oxygenated solvents - ethyl glycol acetate, butyl acetate and ethyl acetate) in the $\mathrm{OH} / \mathrm{NCO}$ proportions $1: 2$ and $1: 3$ were investigated in $3.5 \% \mathrm{NaCl}$ solution. The PEC1 H3 1:2 and PEC1 H3 1:3 coatings showed superior performance. Although thinner than PEC1 H3 1:2, the PEC1 H3 1:3, which contained higher quantity of H3, was the most protective coating. This result was attributed to the higher amount of pre-polymer (H3) that may have increased the crosslinking structure, hindering electrolyte uptake through pores and defects of the coating that delayed the corrosion onset.

An estimation of porosity of coatings can be done from electrochemical results using several approaches depending on if the substrate is active or not [22-27]. The measured current density on the coating/substrate system is equal to the sum of the anodic and cathodic partial current densities at the coating/electrolyte and substrate/electrolyte interfaces, respectively. Equations are normally developed for active substrates because they take into consideration the fraction of the substrate surface exposed to the electrolyte, but can also be obtained for inert and passive coatings. Therefore, the porosity of coatings can be estimated by using different electrochemical techniques such as linear polarization, Tafel plots, potentiodynamic polarization and electrochemical impedance spectroscopy [22-27]. Notter and Gabe [28] clearly described the nature and effect of porosity on the corrosion resistance of electrodeposited coatings. The methods developed for detecting porosity of coatings may be divided into three main categories: physical porosity tests using microscopy; chemical methods using different test reagents [28] and electrochemical methods
[22,28-35]. These results encouraged us to estimate the porosity of the coatings by using electrochemical techniques.

Moreover, in this work, the localized corrosion activity on artificially-induced defects was studied by SVET and LEIS. The corroded surface was observed by scanning electron microscopy (SEM) and analyzed by energy dispersive X-ray (EDX) analysis.

\section{Experimental}

\subsection{Materials}

The ASTM $1200 \mathrm{H} 14$ aluminum alloy (Biometal S.A.) has the following nominal chemical composition (wt\%): $0.05 \mathrm{Cu}$, $(\mathrm{Fe}+\mathrm{Cr}+\mathrm{Si}+\mathrm{Mg}=0), 0.05 \mathrm{Mn}, 0.05 \mathrm{Ti}, 0.10 \mathrm{Zn}$, other components $0.5-0.15$, and balance Al. The surface of the Al alloy plates $(10 \mathrm{~cm} \mathrm{x}$ $10 \mathrm{~cm}$ ) was successively wet-ground down to 1200 gradation using silicon carbide sandpaper. Between each grind step, the sample surface was thoroughly washed with distilled water, rinsed with acetone and at the last step gently wiped with filter paper and stored in desiccator. Then, the organic films were applied on the surface by an applicator, and subjected to cure at room temperature for $24 \mathrm{~h}$ (see details in Supplementary material).

\subsection{Organic films preparation (details in 1S. Supplementary material)}

Organic films prepared with hydroxylated polyesters, obtained from crambe oil modified (PEC1) with trimethylolpropane (TMP) and phthallic anhydride ( $\mathrm{PhA})$, and the pre-polymer $\mathrm{H} 3$ composed by hexamethylene diisocyanate (HDI), castor oil (CAO), propane glycol (PG) and in oxygenated solvents such as ethyl acetate + butyl acetate + ethyl glycol acetate were blended in weight proportions $1: 2$ or $1: 3$ to give the coatings: PEC1 H3 1:2; PEC1 H3 1:3, respectively [18], which are described in Table 1. 
PEC1 H3 1:2
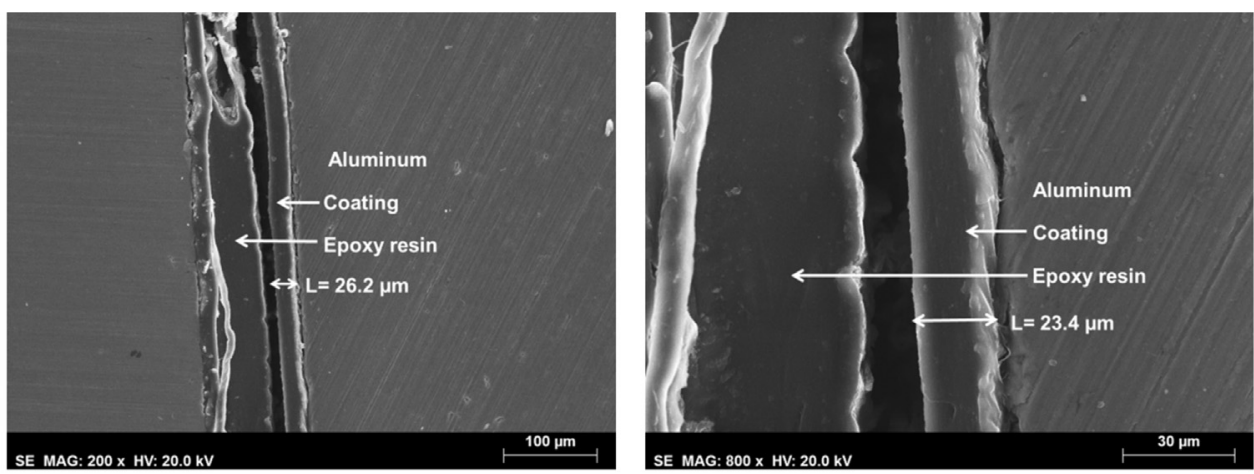

PEC1 H3 1:3
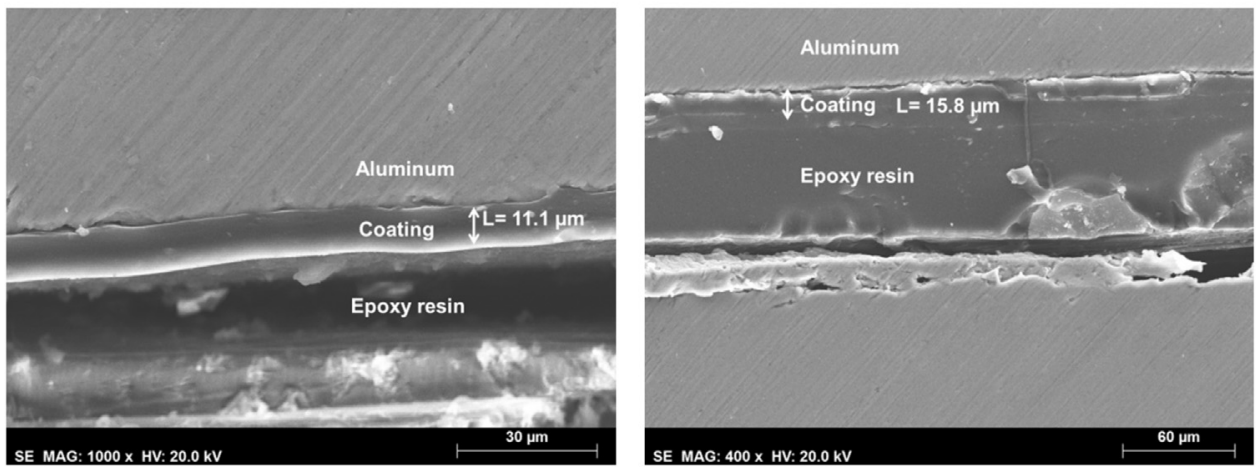

Fig. 2. SEM cross-section images for PEC1 H3 1:2 and PEC1 H3 1:3 coatings.

\subsection{Electrochemical study}

The electrochemical behavior of the coatings was analyzed by small amplitude linear polarization (SALP) measurements, conventional electrochemical impedance spectroscopy (EIS) and the electrochemical localized techniques: LEIS and SVET.

For SALP and EIS, a conventional three-electrode electrochemical cell Model K0235, in which bare and coated aluminum alloy (geometrical area of $1 \mathrm{~cm}^{2}$ exposed to the electrolyte) were used as working electrode, an $\mathrm{Ag}|\mathrm{AgCl}| \mathrm{KCl} 3 \mathrm{moll}^{-1}$, connected to the electrolyte through a Luggin capillary, was the reference, and a Pt spiral the auxiliary electrode. All potentials were referred to the $\mathrm{Ag}|\mathrm{AgCl}| \mathrm{KCl} 3 \mathrm{~mol} \mathrm{l}^{-1}$ reference electrode. The electrolyte was an unstirred and non-deaerated $3.5 \mathrm{wt} \% \mathrm{NaCl}\left(\sim 0.6 \mathrm{moll}^{-1}\right)$ aqueous solution, and the measurements were conducted at $25^{\circ} \mathrm{C}$. The linear polarization curves were obtained in triplicate with a scan rate $0.166 \mathrm{mV} \mathrm{s}^{-1}$ (ASTM G59-97) in the potential range of $\pm 20 \mathrm{mV} / E_{\mathrm{OCP}}$ after 30 min of immersion. The polarization resistance, $R_{\mathrm{p}}$ was used to estimate the coatings porosity $(P)$, understood as the active fraction area of the coated electrode accessed by the electrolyte. The $P$ values were estimated from the impedance modulus and solution resistance: $|Z|_{5 \mathrm{mHz}}-R_{\mathrm{S}}$ taken from the impedance modulus - frequency plots for short immersion times. Conventional EIS measurements were performed during longer immersion times, up to a sharp decreasing of the $E_{\mathrm{OCP}}$ value [18], using a GAMRY REF 600 potentiostat/galvanostat by applying a $10 \mathrm{mV}$ (r.m.s.) sinusoidal potential perturbation signal to $E_{\mathrm{OCP}}$, from $1 \times 10^{5} \mathrm{~Hz}$ to $5 \times 10^{-3} \mathrm{~Hz}$, and recording 10 points/frequency decade. These data were employed to evaluate the coatings performance with the immersion times.
SVET and LEIS studies of the coatings were performed, respectively, in 0.05 and $0.005 \mathrm{moll}^{-1} \mathrm{NaCl}$ aqueous solution for $24 \mathrm{~h}$ at $25^{\circ} \mathrm{C}$. Prior to the electrochemical study the samples were washed with ultrapure water (Millipore quality, $\rho>18 \mathrm{M} \Omega \mathrm{cm}$ ) and dried with pure argon. Samples of proper sizes were cut using a BUEHLER Diamond Wafer Blade Series 15LC diamond no. 11-4276 system. Prior to the localized corrosion studies the conductivity of the solution was measured using an EUTECH INSTRUMENTS PC700 conductivimeter.

\subsection{SVET measurements}

The measurements were performed using a SVET system from Applicable Electronics Inc., controlled by the ASET software (Science Wares). To perform the measurements, the samples were glued to a holder and the exposed area (a square of approximately $1 \mathrm{~mm}^{2}$ ) was delimited by insulating the remaining surface using a mixture of beeswax. The current density maps were measured by scanning the microelectrode over the scratched and non-scratched areas. The scratch $(\approx 0.5 \mathrm{~mm}$ long $\mathrm{x} \approx 0.2 \mathrm{~mm}$ large $)$ was done with a microindenter by applying $5.4 \mathrm{~N}$, allowing exposing the bare metal. The exposed area was continuously assessed with a microscopic video system and the measurements were performed in a $36 \times 36$ grid, generating 1296 points. An insulated Pt-Ir probe, with platinum black deposited on a spherical tip of $10 \mu \mathrm{m}$ diameter and coated with polymeric material, was used as vibrating electrode. The probe was placed $100 \pm 3 \mu \mathrm{m}$ above the surface, vibrating in the planes perpendicular $(\mathrm{Z})$ and parallel $(\mathrm{X})$ to the surface of the sample with the probe vibration frequencies of $124 \mathrm{~Hz}$ and $325 \mathrm{~Hz}$, respectively. Only the data collected at the vibration perpendicular (Z) to the sample was considered and presented in this work. 
Table 2

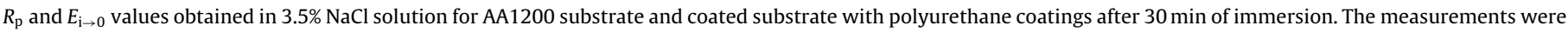
done in triplicate, and three linear polarization curves were obtained for each sample.

\begin{tabular}{|c|c|c|c|}
\hline Sample & $R_{\mathrm{p}, \mathrm{s}}$ and $R_{\mathrm{p}, \text { coat-s }}\left(\Omega \mathrm{cm}^{2}\right)$ & $R_{\mathrm{p}} /\left(\Omega \mathrm{cm}^{2}\right)\left(|\mathrm{Z}|_{5 \mathrm{mHz}}\right)$ & $E_{\mathrm{i} \rightarrow 0} /\left(\mathrm{V}\right.$ vs. $\left.\mathrm{Ag}|\mathrm{AgCl}| \mathrm{KCl} 3 \mathrm{moll}^{-1}\right)$ \\
\hline Al alloy & $\left(4.0 \times 10^{3} \pm 0.5 \times 10^{3}\right)$ & $4 \times 10^{3}$ & $(-0.684 \pm 0.001)$ \\
\hline PEC1 H3 1:2 & $\left(1.10 \times 10^{8} \pm 0.02 \times 10^{8}\right)$ & $2.3 \times 10^{7}$ & $(-0.067 \pm 0.003)$ \\
\hline PEC1 H3 1:3 & $\left(2.64 \times 10^{7} \pm 0.03 \times 10^{7}\right)$ & $3.2 \times 10^{7}$ & $(-0.090 \pm 0.002)$ \\
\hline
\end{tabular}

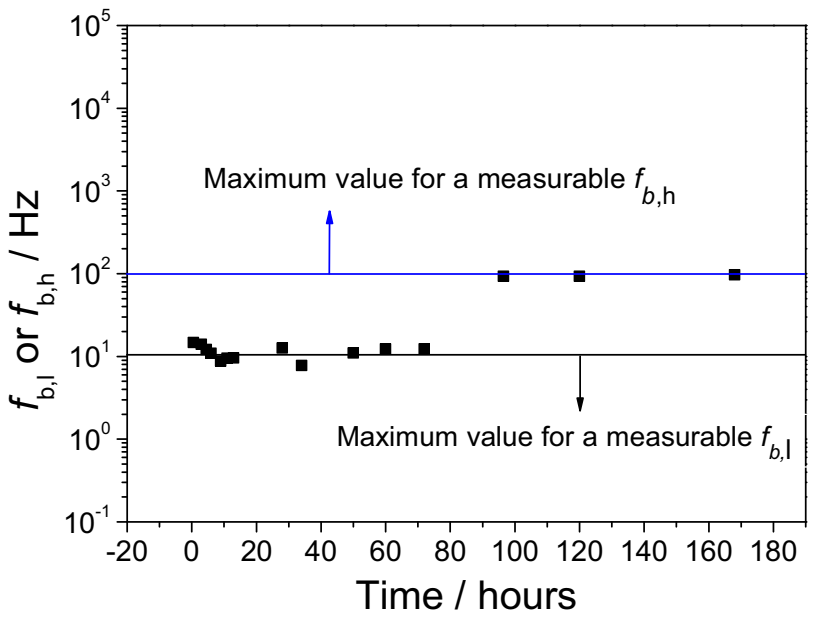

(A)

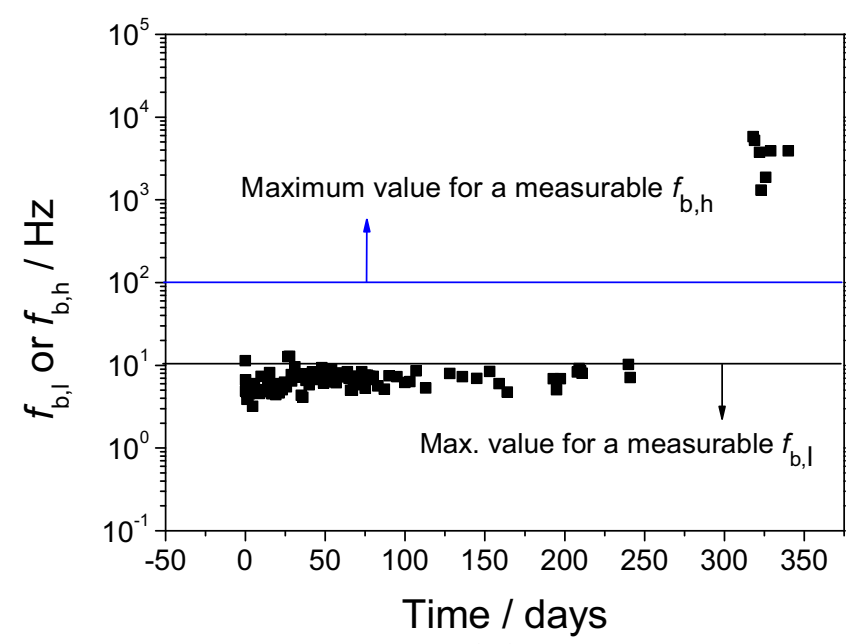

(B)

Fig. 3. Effect of the exposure time on the breakpoint frequency $f_{\mathrm{b}, \mathrm{l}}$ or $\mathrm{f}_{\mathrm{b}, \mathrm{h}}$.

\subsection{LEIS measurements}

LEIS measurements were performed with a Solartron 1286 electrochemical interface with a Solartron 1250 frequency response analyzer coupled with a Uniscan electrochemical station. The LEIS system was composed of five electrodes, consisting of a conventional three-electrode arrangement (reference electrode, counter electrode, and the coated sample as working electrode under a potentiostatic control) and a Pt bi-electrode (LEIS probe) to measure the local potential gradient in solution above the surface. The reference electrode was a saturated calomel electrode (SCE) and the counter electrode was a Pt mesh. The distance between the two electrodes of the LEIS probe was $1.5 \mathrm{~mm}$. The probe was placed close, as possible, to the sample surface, being the same distance for both point and area scan for each coating. The potential difference was measured between the reference and working electrodes (i.e., the potential of the working electrode). Details on the customized configuration of the LEIS probe used in this work have been previously described [36]. The probe was stepped across a well-defined area of the sample including the scratch. After point scan measurements on the coating and defected region $(\approx 6 \mathrm{~mm}$ long $\mathrm{x} \approx 0.3 \mathrm{~mm}$ large) at different frequencies, an excitation frequency of $5 \mathrm{kHz}$ was chosen for obtaining the LEIS maps (area scan: 32 points $\times 16$ lines) in diluted $\mathrm{NaCl}$ solution $\left(\rho=0.000607 \mathrm{Scm}^{-1}\right)$ each $2 \mathrm{~h}$ for $25 \mathrm{~h}$ of immersion. The surface area exposed to the solution was $\approx 10 \mathrm{~mm}^{2}$. All electrochemical studies were conducted at $25^{\circ} \mathrm{C}$.

\subsection{Morphological analysis and thickness}

The coatings were previously characterized by Fourier Transform Infrared Attenuated Total Reflectance (FTIR-ATR) before and after applying high anodic polarization potentials and no significant changes in the spectra were observed [18].

The coating surface was analyzed before and after testing by scanning electron microscopy (SEM) using FEG-SEM JEOL model JSM 7001 microscope. SEM images were obtained at $15 \mathrm{kV}$. The coating surface was also analyzed, before and after SVET and LEIS measurements using a digital LEICA model DMS300 microscope.

The thicknesses of the coatings were determined from crosssection images obtained with a scanning electron microscope Hitachi (SEM/S-2400) using $20 \mathrm{kV}$.

\section{Results and discussion}

\subsection{Thickness of coatings, coatings porosity and performance}

Fig. 1 depicts the micrographs of the polyurethane coating applied on ASTM $1200 \mathrm{H} 14$ aluminum alloy. It is possible to see that the surface did not evidence cracks, even when SEM images were taken with $10 \mu \mathrm{m}$.

Fig. 2 shows the cross-section images of both PEC1 H3 1:2 and PEC1 H3 1:3 coatings. The determined thicknesses were between 26.2 and $23.4 \mu \mathrm{m}$ for PEC1 H3 $1: 2$ and from 11.1 to $15.8 \mu \mathrm{m}$ for PEC1 H3 1:3, respectively.

Based on the thickness values PEC1 H3 1:2 would be able to offer higher barrier effect. However, cyclic polarization [18] and conventional EIS measurements indicated that PEC1 $\mathrm{H} 3$ $1: 3$ provided better corrosion protection in aerated $3.5 \mathrm{wt} \%$ $\mathrm{NaCl}$ solution. The values of $E_{\text {corr }}$ and $i_{\text {corr }}$ were, respectively, $-0.11 \mathrm{~V} / \mathrm{Ag}|\mathrm{AgCl}| \mathrm{KCl} 3 \mathrm{moll}^{-1}$ and $1.8 \times 10^{-9} \mathrm{~A} \mathrm{~cm}^{-2}$ (PEC1 H3 1:2), and $-0.05 \mathrm{~V} / \mathrm{Ag}|\mathrm{AgCl}| \mathrm{KCl} 3 \mathrm{moll}^{-1}$ and $1.6 \times 10^{-9} \mathrm{~A} \mathrm{~cm}^{-2}$ (PEC1 H3 $1: 3$ ) after $1 \mathrm{~h}$ of immersion. At low frequencies, the modulus of impedance for the PEC1 H3 1:2 sample was around $3 \times 10^{7} \Omega \mathrm{cm}^{2}$ for $t<50 \mathrm{~h}$, and $\sim 5 \times 10^{6} \Omega \mathrm{cm}^{2}$ for $t>60 \mathrm{~h}$ of immersion, while for PEC1 H3 $1: 3$ it was around $6 \times 10^{7} \Omega \mathrm{cm}^{2}$ for $t<243$ days, and decreased to $|Z| \cong 3 \times 10^{6} \Omega \mathrm{cm}^{2}$ for $\mathrm{t}>300$ days of immersion [18]. The higher content of $\mathrm{H} 3$ pre-polymer allowed higher cross-linking, and, as the PEC1 H3 1:3 coating was thinner than PEC1 H3 1:2, a more closed and rigid structure is expected. This may be the reason for extending the life time of this coating to around 250 days before failure, while PEC1 H3 1:2 failed in a few days. It was also mentioned that if a more closed structure is present in the PEC1 


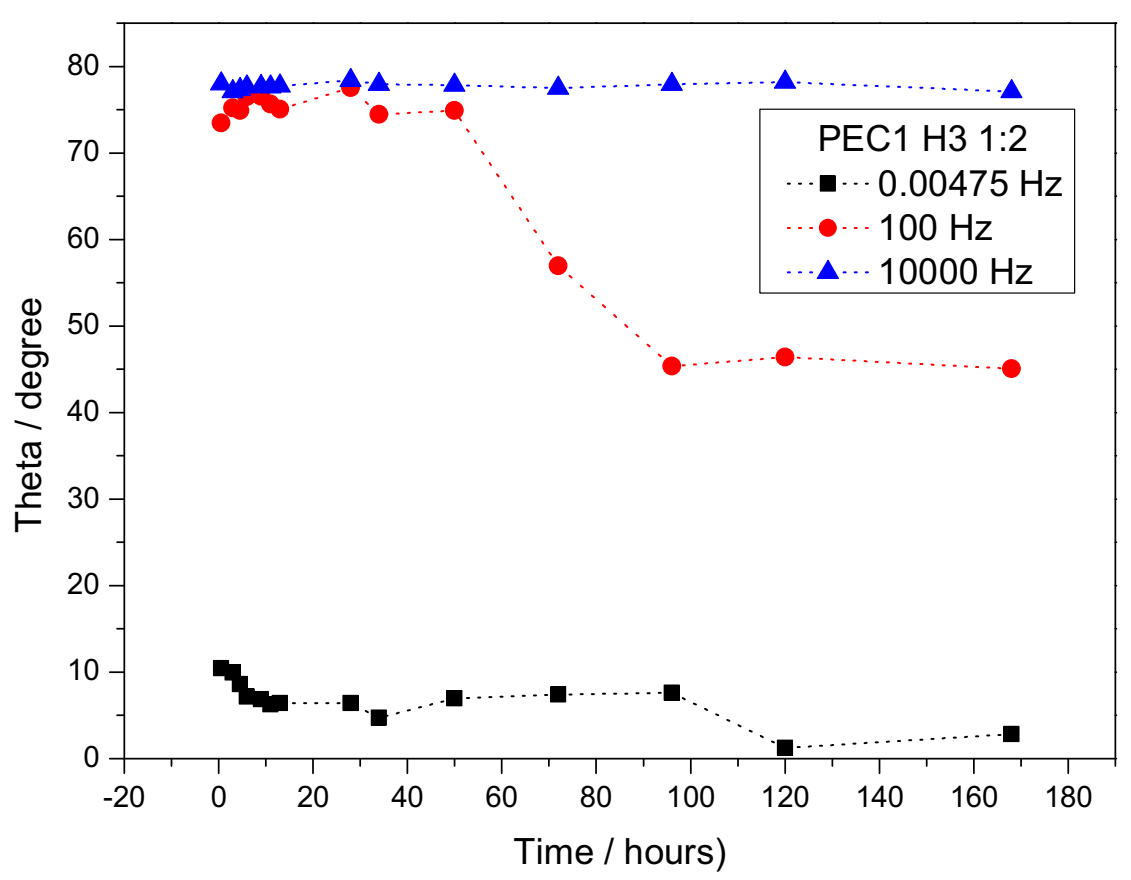

(A)

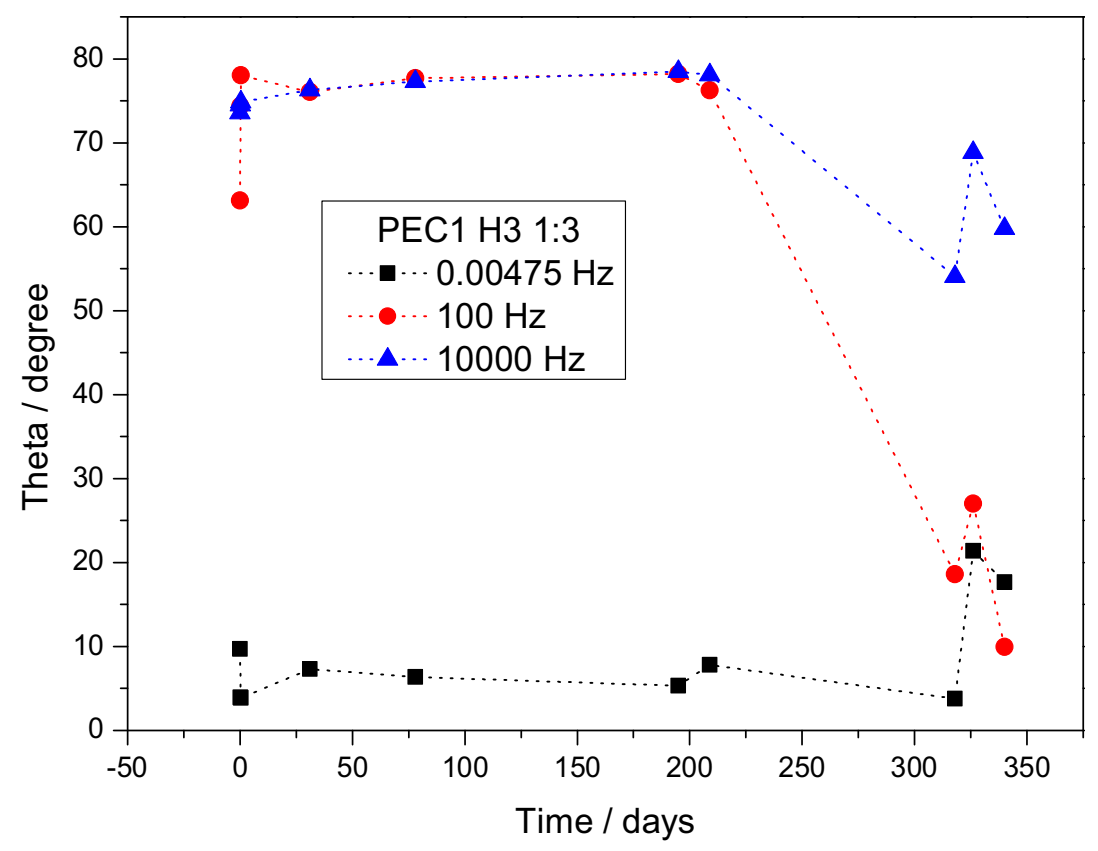

(B)

Fig. 4. Phase angle (theta) at low, medium and high frequencies with immersion time, in $3.5 \mathrm{wt} \% \mathrm{NaCl}$ soluiton.

H3 1:3 coating, it will delay electrolyte uptake as a consequence of lower porosity and/or smaller pores, which would promote pore blocking at early corrosion stage [18]. Thus, estimation of porosity at short immersion times is relevant to characterize the barrier properties of the coating.

The fraction of the substrate area exposed to the electrolyte (porosity) was estimated from the $R_{\mathrm{p}}$ values measured from small amplitude linear polarization (SALP) and from electrochemical impedance [37]. For a passive or electrochemically inert coating, the porosity $(P)$, can be given by the ratio of the polarization resistances of the coated $\left(R_{\mathrm{p}, \text { coat-s }}\right)$ and uncoated $\left(R_{\mathrm{p}, \mathrm{s}}\right)$ samples [26]. Therefore,

$P=\frac{R_{\mathrm{p}, \mathrm{s}}}{R_{\mathrm{p}, \text { coat }-\mathrm{s}}}$ 


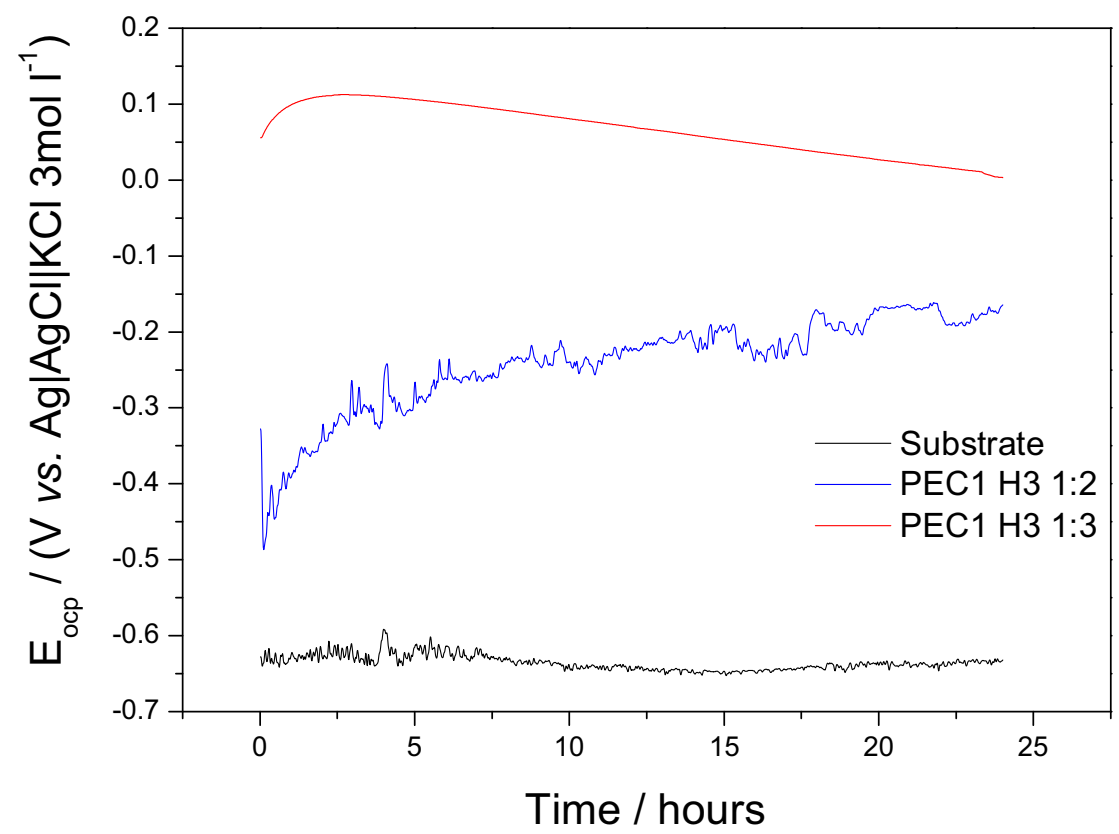

(A)

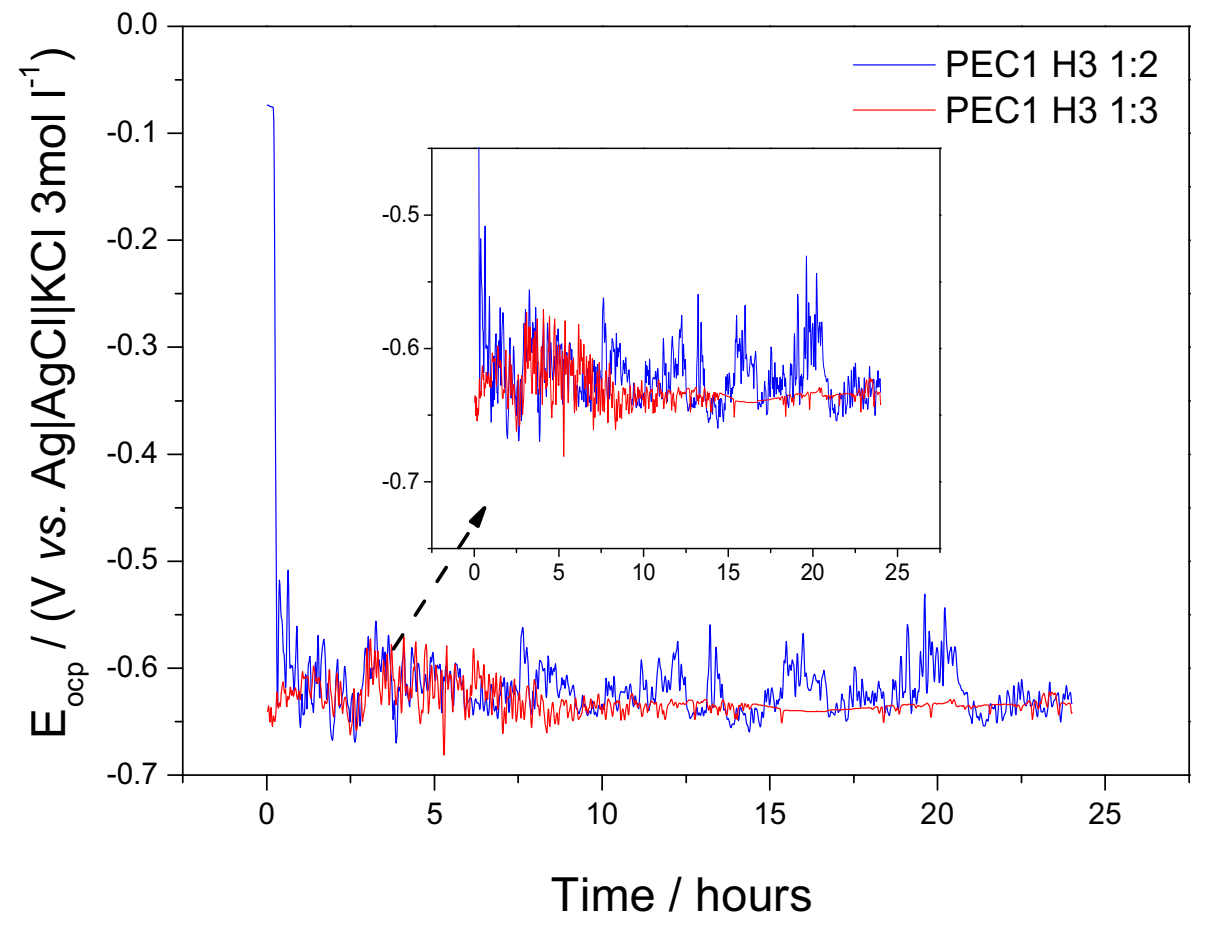

(B)

Fig. 5. EOCP vs. time for samples: PEC1 H3 1:2 and PEC1 H3 1:3 coatings in aerated 0.05 moll ${ }^{-1} \mathrm{NaCl}$ solution for $24 \mathrm{~h}$ : (A) scratch-free; (B) with scratch $\sim 1 \mathrm{~mm}$. 

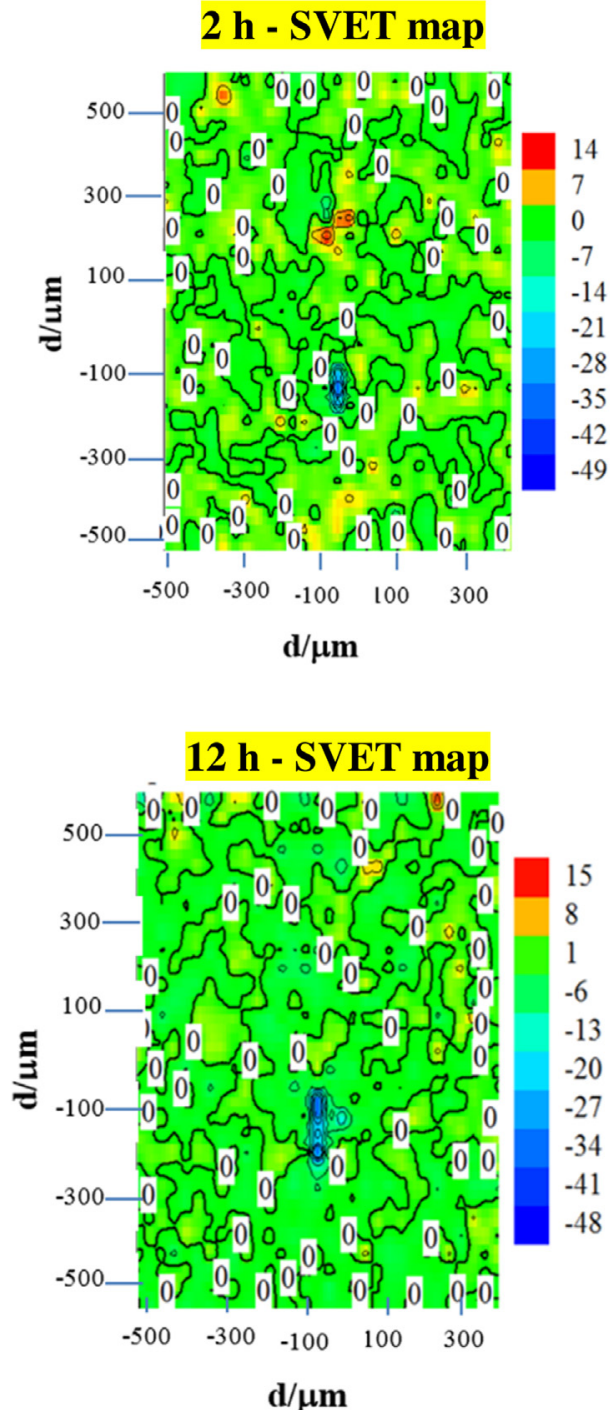
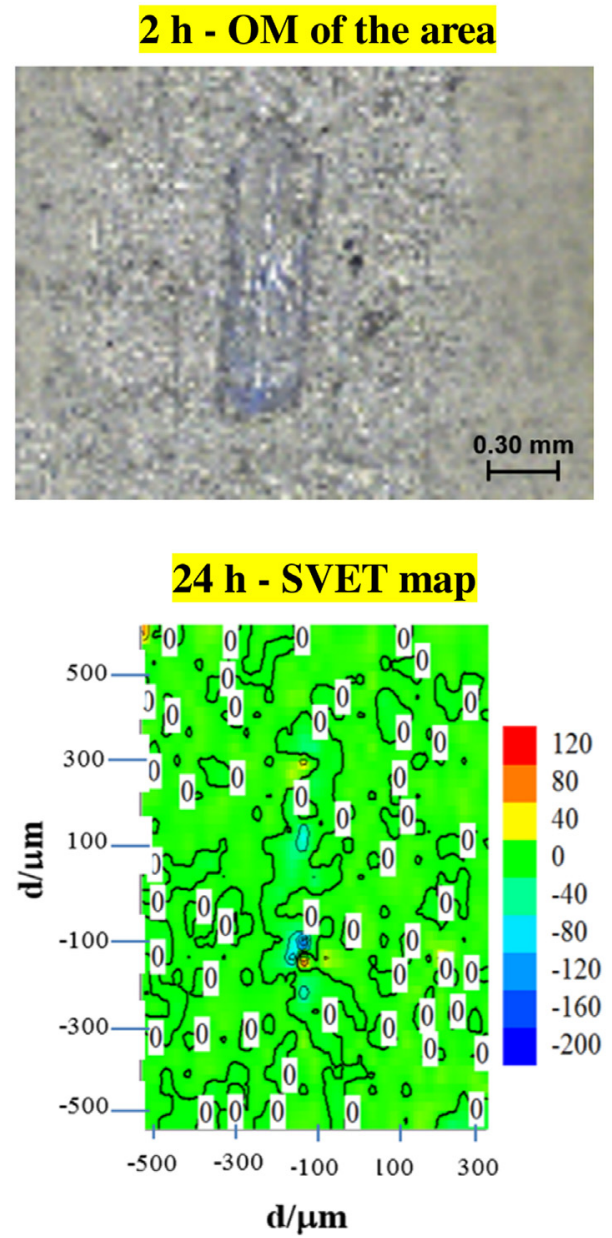

(A)

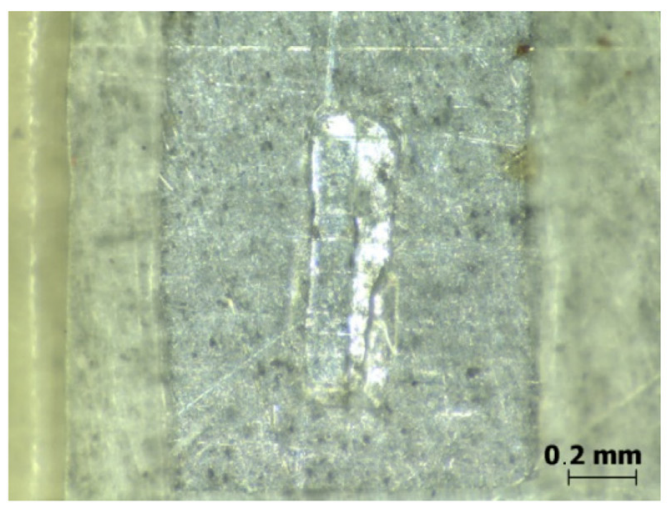

(B)

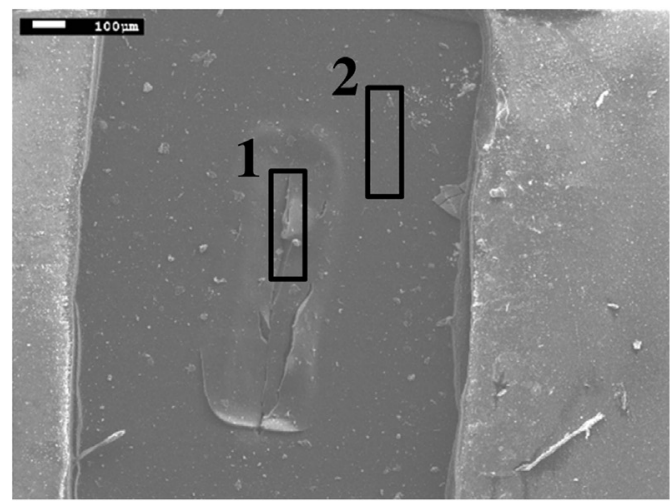

(C)

Fig. 6. (A) SVET maps of scratch artificially generated on the PEC1 H3 $1: 2$ coating, obtained in $0.05 \mathrm{~mol}^{-1} \mathrm{NaCl}$ solution for different times. Current density in $\mu \mathrm{A} / \mathrm{cm}^{2}$ and optical micrograph of the same area; (B) Optical micrograph of the surface at the end of SVET experiments (24h), and (C) SEM imagens after SVET measurements for $24 \mathrm{~h}$. 
being,

$R_{\mathrm{p}, \text { coat-s }}=\left(\frac{\mathrm{d} E}{\mathrm{~d} i_{\text {coat-s }}}\right)$

and

$R_{\mathrm{p}, \mathrm{s}}=\left(\frac{\mathrm{d} E}{\mathrm{~d} i_{\mathrm{s}}}\right)_{\mathrm{E}(\mathrm{i} \rightarrow 0)}$

$P$ represents the fraction of the substrate exposed to the electrolyte (area of the defected coating, $\left.A_{\mathrm{d}}\right)$ in relation to the total area $\left(A_{\text {total }}\right)$ of the electrode. It means that

$R_{\mathrm{p}, \text { coat }-\mathrm{s}}=\frac{R_{\mathrm{p}, \text { coat }-\mathrm{s}}^{0}}{A_{\mathrm{d}}}$

and

$R_{\mathrm{p}, \mathrm{s}}=\frac{R_{\mathrm{p} . \mathrm{s}}^{0}}{\mathrm{~A}_{\mathrm{total}}}$

where $R^{0}$ p-coat-s is the polarization resistance per unit area of the defected coating, $A_{\mathrm{d}}$ is the defected area of the coated sample exposing the substrate to the electrolyte, $R_{\mathrm{p}, \mathrm{s}}^{0}$ is the polarization resistance per unit area of the substrate and $A_{\text {total }}$ is the total area of the electrode. Table 2 shows the polarization resistances $\left(R_{\mathrm{p}}\right)$ determined from the small amplitude linear polarization after $30 \mathrm{~min}$ of immersion used to estimate the porosity and the potential at $\mathbf{I} \rightarrow \mathbf{0}$. This potential is different of $\mathrm{E}_{\text {corr }}$ since it is measured at short immersion times, when the system is not stable yet.

Coatings studied in this work can be considered electrochemically inert and the substrate behaves as a passive system until chloride ions reach the coating/substrate interface, damaging the aluminum oxide film. Previous studies indicated that PEC1 H3 1:2 and PEC1 H3 1:3 coatings provided protection, respectively, at least for the first 2 and 250 days of immersion in $3.5 \% \mathrm{NaCl}$ solution [18]. It means that polarization resistances determined after short immersion times ( $30 \mathrm{~min}$ ) can be related to the small pores present in the coating and, therefore can be used to estimate the porosity of the coating. By using Eq. (1) the porosity was estimated to be $0.004 \%$ for PEC1 H3 1:2 and 0.015\% for PEC1 H3 1:3. Porosity values were also obtained from the impedance diagrams (Supplementary material, Fig. 2S) using the modulus of impedance $|Z|$ at low frequency $\left(5 \mathrm{mHz}\right.$ ) for short immersion time (30 min): $2.3 \times 10^{7} \Omega \mathrm{cm}^{2}$ (PEC1 H3 1:2) and $3.2 \times 10^{7} \Omega \mathrm{cm}^{2}$ (PEC1 H3 1:3), resulting in the porosity values of $0.017 \%$ and $0.013 \%$, respectively, which are in reasonable agreement with the those obtained from SALP.

Conventional EIS measurements as function of immersion time were also obtained for both PEC1 H3 1:2 and PEC1 H3 1:3 coatings in $3.5 \mathrm{wt} \%\left(\sim 0.6 \mathrm{moll}^{-1}\right) \mathrm{NaCl}$ aqueous solution. Figs. $1 \mathrm{~S}$ and $2 \mathrm{~S}$ (Supplementary material) illustrate, respectively, some complex plane and Bode plots in the absence of an artificial scratch. The performance of the coated samples was also evaluated using different procedures of analysis of conventional EIS measurements with the immersion time. One of them was based on the breakpoint frequency concept [38] and applied to evaluate different coatings $[35,39,40]$. The breakpoint frequency $f_{\mathrm{b}}$ is the frequency at which the phase angle firstly falls to $45^{\circ}$ and can show a good correlation between $f_{\mathrm{b}}$ and the delaminated area of the coating from the metal substrate [38]. It represents the boundary where occurs the first transition from a capacitive region to a resistive region when the frequency goes from high to low values. Fig. 3 shows the breakpoint frequency values for PEC1 H3 1:2 (Fig. 3A) and PEC1 H3 1:3 (Fig. 3B) coatings, in which it can be seen that the transition occurs at medium-high frequency after around $70 \mathrm{~h}$ and 240 days of immersion for PEC1 H3 1:2 and PEC1 H3 1:3 coatings, respectively. The PEC1 H3 1:3 coating showed higher performance. Taking in consideration the behavior of PEC1 H3 1:2, the value of maximum $f_{\mathrm{b}, \mathrm{h}}$ was considered as the frequency where the corrosion spot at
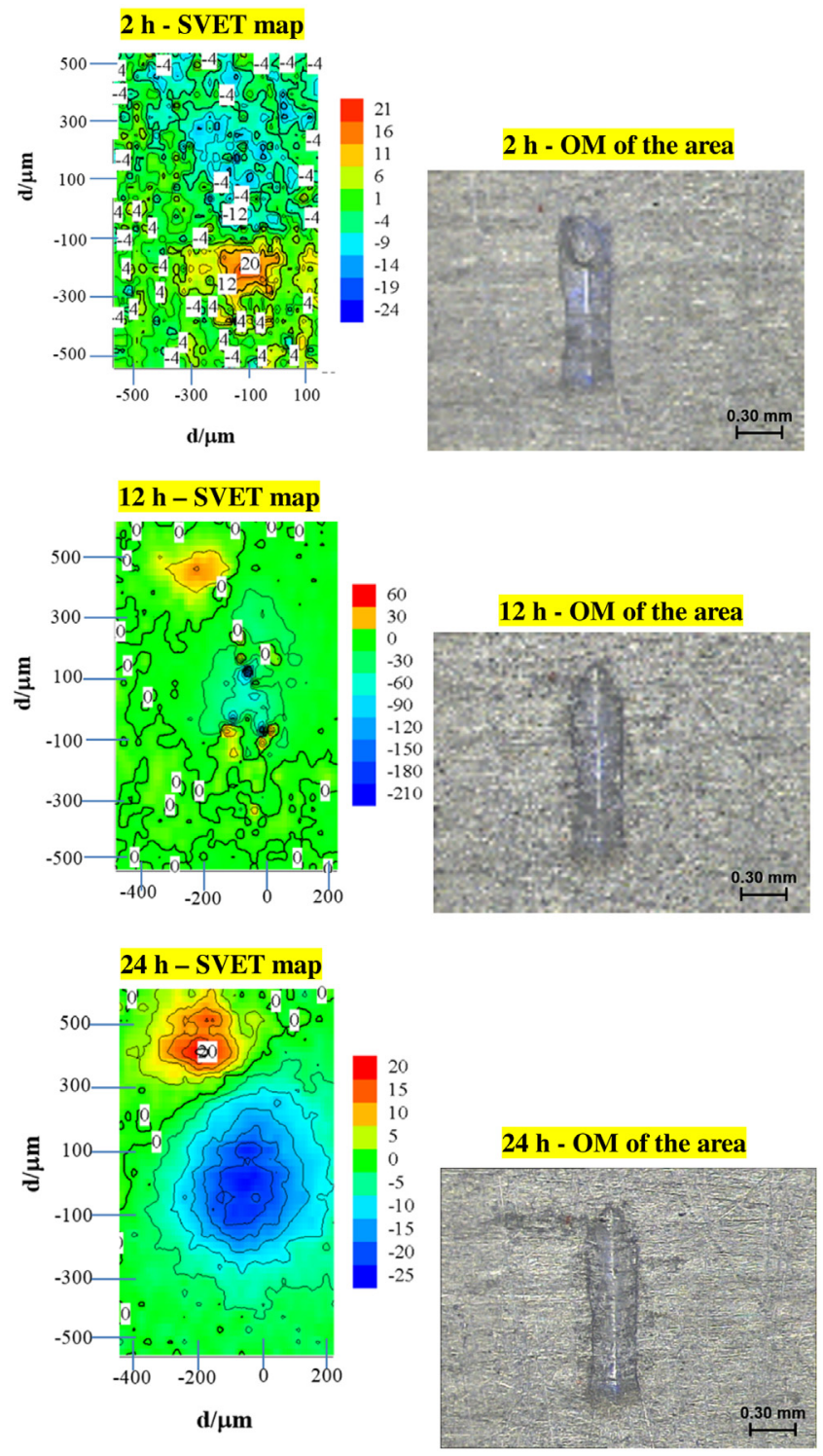

(A)

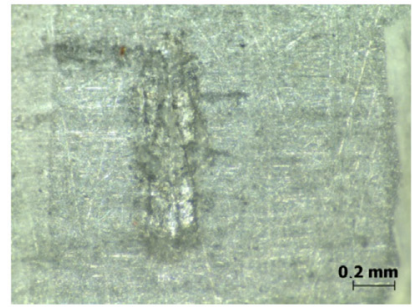

(B)

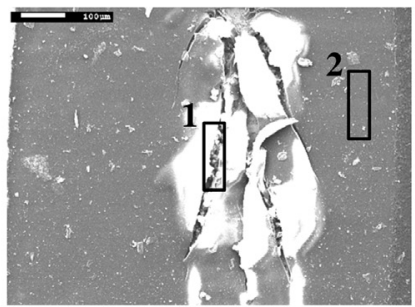

(C)
Fig. 7. (A) SVET maps of scratch artificially generated on the PEC1 H3 1:3 coating, obtained in $0.05 \mathrm{moll}^{-1} \mathrm{NaCl}$ solution. Current density in $\mu \mathrm{A} / \mathrm{cm}^{2}$ and micrographs of the same area; (B) Optical micrograph of the surface at the end of SVET experiments (24 h), and (C) SEM imagens after SVET measurements for $24 \mathrm{~h}$.

the substrate was first observed, and then around $10 \mathrm{~Hz}$ was considered the limit of $f_{\mathrm{b}, 1}$. The fact that the $f_{\mathrm{b}, \mathrm{h}}$ is not so high at long immersion times suggests that only small fractions of the coatings were damaged.

The phase angle variation at high, medium and low frequency values [41,42] can also be used to evaluate the coating performance. Fig. 4 shows the variation of the phase angle at $\sim 5 \mathrm{mHz}, 100 \mathrm{~Hz}$ 


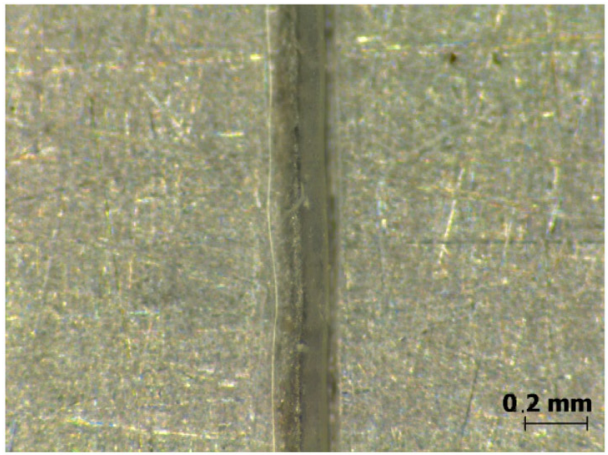

(A)

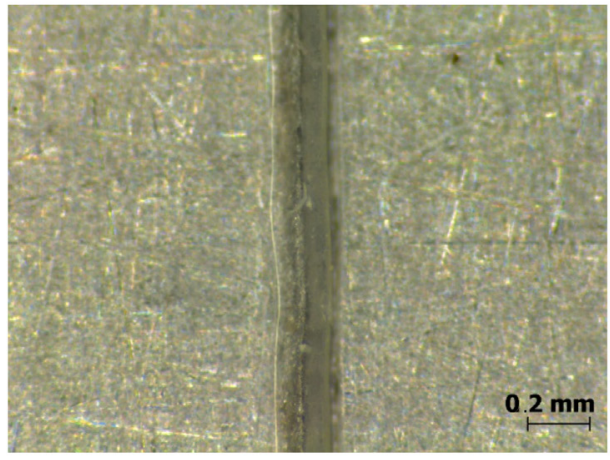

(C)

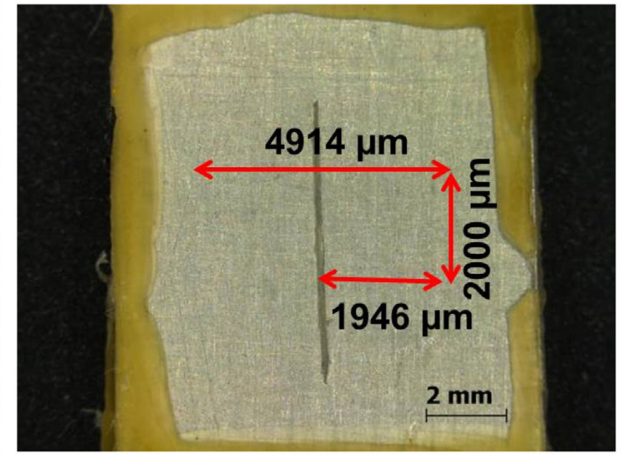

(B)

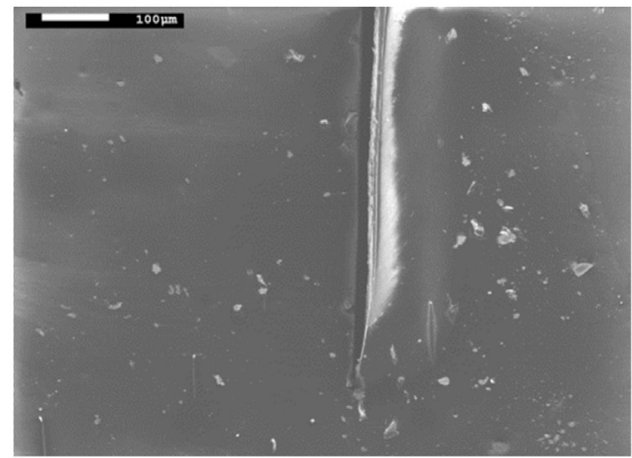

(D)

Fig. 8. Images of PEC1 H3 1:2 surfaces obtained before ( $A$ and B) and after ( $C$ and D) LEIS measurements in $0.005 \mathrm{moll}^{-1} \mathrm{NaCl}$ solution for $25 \mathrm{~h}$. (A, B and C) optical and (D) SEM images. (B) Area scan measurement.

and $10 \mathrm{kHz}$ frequencies for PEC1 H3 1:2 (Fig. 4A) and PEC1 H3 1:3 (Fig. 4B) coatings.

For PEC1 H3 1:2 the phase angle values decreased slowly with time at high frequencies, decreased at medium frequencies (around $100 \mathrm{~Hz}$ ) after from 60 to $72 \mathrm{~h}$ of immersion and were very low at low frequency values. The variation of the phase angle at medium frequency and the change in $f_{\mathrm{b}, \mathrm{l}}$ values occurred at approximately the same immersion time, indicating that both may be related to the coating performance. For PEC1 H3 1:3 similar behavior was observed, however, the changes were observed near 250 days of immersion.

Fig. 5 shows the $E_{\mathrm{OCP}}$ variation for the PEC1 H3 1:2 and PEC1 H3 1:3 coatings during $24 \mathrm{~h}$ of immersion in unstirred and nondeaerated $0.05 \mathrm{moll}^{-1} \mathrm{NaCl}$ solution, the same condition of SVET measurements. In the absence of scratch the $E_{\mathrm{OCP}}$ values for PEC1 $\mathrm{H} 31: 2$ increased with time from -0.5 to $\sim-0.17 \mathrm{~V} v s$. $\mathrm{Ag}|\mathrm{AgCl}| \mathrm{KCl}$ $3 \mathrm{moll}^{-1}$ while for PEC1 H3 1:3 remained between 0.10 and $0.0 \mathrm{~V}$ vs. $\mathrm{Ag}|\mathrm{AgCl}| \mathrm{KCl} 3 \mathrm{moll}^{-1}$, indicating that the electrolyte did not reached the substrate. The $E_{\mathrm{OCP}}$ values for both PEC1 H3 1:2 and $1: 3$ are much more positive than the value measured for the substrate $\left(-0.65 \mathrm{~V} v\right.$ s. $\left.\mathrm{Ag}|\mathrm{AgCl}| \mathrm{KCl} 3 \mathrm{moll}^{-1}\right)$. The potential difference can be related to the barrier effect of the coating bringing a large IR drop. The high barrier effect may also suggest high ability of the coatings to protect the substrate against corrosion in the chloride solution. In fact it was demonstrated for PEC1 H3 1:3 (Fig. 2S) which showed a modulus of impedance higher than $5 \times 10^{7} \Omega \mathrm{cm}^{2}$ even at higher $\mathrm{NaCl}$ concentration. When a scratch was done on the surface of the coatings, the $E_{\mathrm{OCP}}$ for PEC1 H3 1:2 decayed from near -0.05 to $\sim-0.6 \mathrm{~V}$ vs. $\mathrm{Ag}|\mathrm{AgCl}| \mathrm{KCl} 3 \mathrm{moll}^{-1}$ and then oscillated between -0.55 to $-0.64 \mathrm{~V}$, while for PEC1 $\mathrm{H} 31: 3$ the $E_{\mathrm{OCP}}$ was around $-0.64 \mathrm{~V}$ vs. $\mathrm{Ag}|\mathrm{AgCl}| \mathrm{KCl} 3 \mathrm{moll}^{-1}$ all the time, and the amplitude of potential oscillations were lower than for PEC1 H3 1:2 and damped after $7 \mathrm{~h}$.
The oscillation of the open circuit potential for scratched-PEC1 H3 $1: 2$ sample can be due to the attack to the substrate and re-covering of the coating.

\subsection{Corrosion studies by localized techniques}

\subsubsection{SVET study}

3.2.1.1. PEC1 H3 1:2 coating. Fig. 6A depicts illustrative SVET maps and micrographs obtained during the immersion in $0.05 \mathrm{moll}^{-1}$ $\mathrm{NaCl}$ solution. Corrosion products were not visible inside and outside of the scratched regions and the maps did not show significant differences. Only a small anodic spot (at the top of the scratch) and a small cathodic spot (at the bottom) were identified, indicating that the scratch was protected. In Fig. 6B the coating seemed to re-cover the original scratched surface, and with time there was a slight increase of both anodic and cathodic activity, but no relevant damage over the scratch could be identified.

The EDX analysis of the spot 1 (scratch zone in Fig. 6C) showed the following elemental composition: C (7.9 wt\%), O (62.5 wt\%), Na (10.8 wt\%), $\mathrm{Al}$ (2.8 wt\%), Si (4.0 wt\%) and $\mathrm{Cl}(12.1 \mathrm{wt} \%)$ and on the spot 2 (scratch-free zone in Fig. 6C) was: C (7.5 wt\%), O (78.1 wt\%), $\mathrm{Al}$ (9.6 wt\%) and $\mathrm{Si}$ (4.9 wt\%). In and out of the scratch, the quantity of $C$ was the same, indicating that the coating re-covered great part of the damaged coating, while the amount of $\mathrm{O}, \mathrm{Al}$ and $\mathrm{Si}$ were lower in the scratch zone probably due to the presence of the salt from the electrolyte which could deposited on the substrate.

3.2.1.2. PEC1 H3 1:3 coating. Fig. 7 shows SVET maps and optical micrographs at different times from 2 to $24 \mathrm{~h}$ (Fig. $7 \mathrm{~A}$ ), optical (Fig. 7B) and SEM images (Fig. 7C) of the scratched surface of the PEC1 H3 1:3 coating after $24 \mathrm{~h}$ of immersion in chloride solution. The SVET maps showed well defined anodic and cathodic currents, 

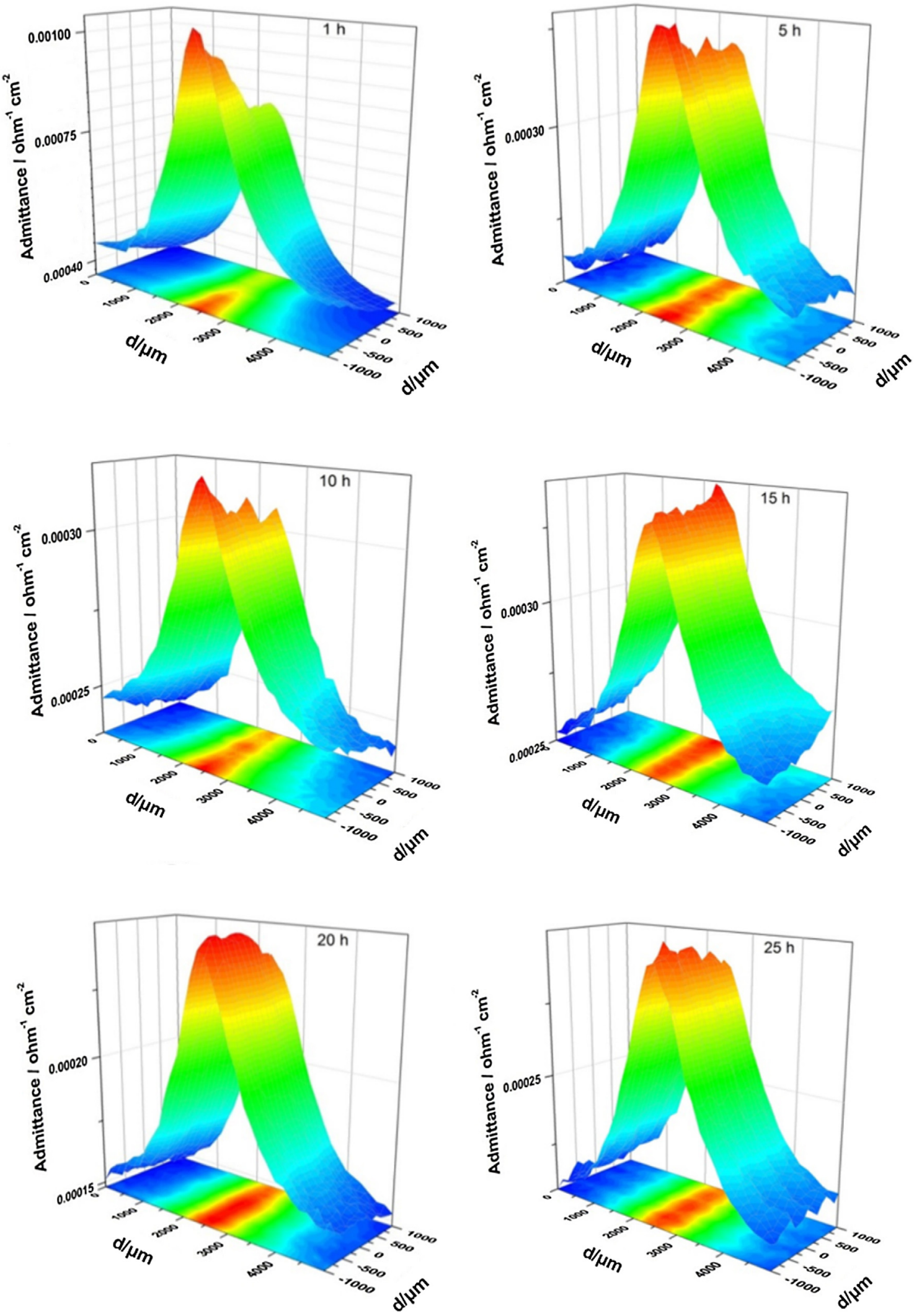

Fig. 9. LEIS maps of the aluminum alloy coated with PEC1 H3 1:2 on both non-scratched and scratched areas in aerated $0.005 \mathrm{moll}^{-1} \mathrm{NaCl}$ solution at different immersion times.

which indicate substrate activity mainly for $\mathrm{t} \geq 12 \mathrm{~h}$ that increased with immersion time. Filiform corrosion was clearly evidenced in the optical micrographs at the end of the experiments. The maps also revealed corrosion propagation, which indicates that the coating protective behavior could not be recovered as before. Moreover, an important accumulation of corrosion products was noticed. The 


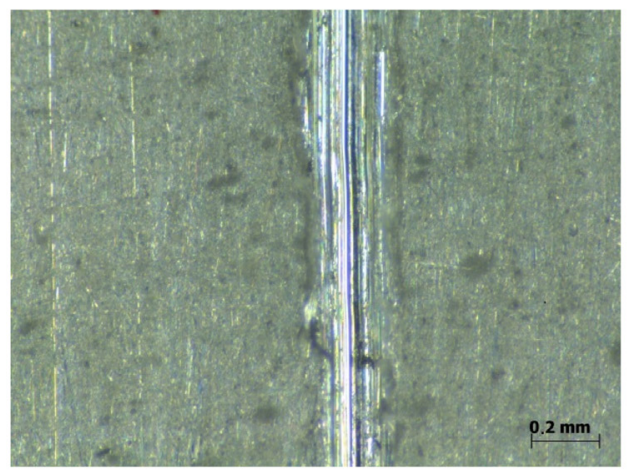

(A)

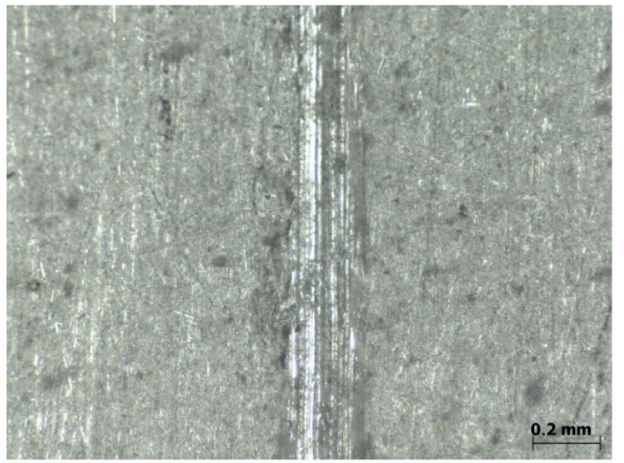

(C)

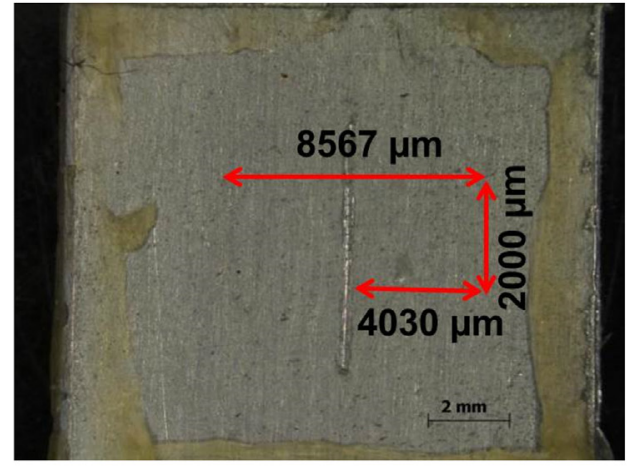

(B)

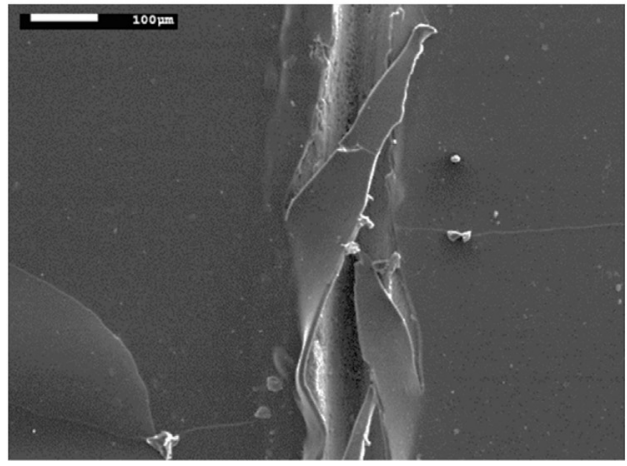

(D)

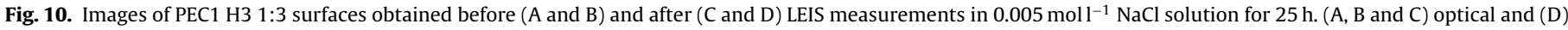
SEM images. (B) Area scan measurement.

corrosion phenomena observed (Fig. 7B and C) is characteristic of filiform-type corrosion in uncoated and coated Al alloys [43-49], due to electrolyte penetration under the coating, causing its delamination.

The EDX analysis of the spot 1 (scratch zone in Fig. 7C) showed the following elemental composition: C (1.4 wt\%), O (57.0 wt\%), Na (3.2 wt\%), $\mathrm{Al}(27.5 \mathrm{wt} \%$ ) and $\mathrm{Cl}(11.1 \mathrm{wt} \%$ ) and on spot 2 (scratch-free zone in Fig. 7C) was: C (9.2 wt\%), O (78.9 wt\%) and $\mathrm{Al}$ (12.0 wt\%). C and $\mathrm{O}$ decreased and $\mathrm{Al}$ increased with the presence of $\mathrm{Cl}$ and small amount of $\mathrm{Na}$ in the scratch zone compared to the scratch-free one. These results indicated that the coating was damaged and was unable to re-covering.

The $\mathrm{NaCl}$ solution $(\mathrm{pH} \approx 7)$ contains dissolved oxygen and the contact with the pure aluminum substrate leads to oxygen reduction, as cathodic reaction, and dissolution of aluminum as anodic reaction [50]:

$\mathrm{O}_{2(\mathrm{~g})}+2 \mathrm{H}_{2} \mathrm{O}_{(\mathrm{l})}+4 \mathrm{e}^{-} \rightarrow 4 \mathrm{OH}^{-}(\mathrm{aq})(6)$

$\mathrm{Al}_{(\mathrm{s})} \rightarrow \mathrm{Al}^{3+}{ }_{(\mathrm{aq})}+3 \mathrm{e}^{-}(7)$

$\mathrm{Al}^{3+}{ }_{(\mathrm{aq})}+3 \mathrm{H}_{2} \mathrm{O}_{(\mathrm{l})} \rightarrow \mathrm{Al}(\mathrm{OH})_{3(\mathrm{~s})}+3 \mathrm{H}^{+}(8)$

Globalreaction : $4 \mathrm{Al}_{(\mathrm{s})}+3 \mathrm{O}_{2(\mathrm{~g})}+6 \mathrm{H}_{2} \mathrm{O}_{(\mathrm{l})} \rightarrow 4 \mathrm{Al}(\mathrm{OH})_{3(\mathrm{~s})}(9)$

The hydrolysis of the aluminum ions decreases the local $\mathrm{pH}$ of the anodic sites making the medium even more aggressive inside the pit [50], and therefore, the corrosion process is accelerated, leading to accumulation of corrosion products and internal stresses. The SEM image (Fig. 7C) suggested that accumulation of corrosion products impeded coating regeneration in the scratched region. The lower thickness and/or higher rigid structure may also be responsible for poor recovery and the PEC1 H3 1:3 was not as protective as the PEC1 H3 1:2.

By analyzing the formulation of PEC1 H3 1:3 and PEC1 H3 1:2 by infrared spectroscopy, Nardeli et al. [18] concluded that these coatings do not show NCO-free groups [51], and it is known that the presence of trimethylolpropane (TMP) and anhydride phthalic $(\mathrm{AF})$ in PEC1 extends the chain and increases the crosslinking. The greater amount of $\mathrm{N}-\mathrm{CO}$ groups in the PEC1 H3 1:3 coating formulation, due to the higher quantity of $\mathrm{H} 3$, results in a more rigid structure and lower thickness (see Fig. 2). The isocyanates are considered to be responsible for the hard part of polyurethanes (PU) structure and aliphatic isocyanates show better elastomeric properties than the aromatic ones [52]. On the other hand, isocyanates are reactive with moisture and have been reported as a very attractive material to develop self-healing coatings [53]. The increase in the amount of $\mathrm{N}-\mathrm{CO}$ groups in the PEC1 H3 1:3 coating formulation results in a more rigid structure and lower thickness [52]. We believe that the relatively lower $\mathrm{N}-\mathrm{CO}$ groups in PEC1 H3 1:2 results in a more open structure that may increase its thickness. On the other hand, the relative greater amount of PEC1 portion in this coating compared to in PEC1 H3 1:3 may increase its flexibility. The triglycerides derivatives, as crambe oil, also contribute to the higher number of $\mathrm{OH}$ groups [54], which can be consumed by the humidity and by the increase of NCO groups. As mentioned above, in the proposed coatings there are no $\mathrm{N}-\mathrm{CO}$-free groups [18,48], the self-healing may occur by hydrogen bonds formation between $\mathrm{OH}$ groups of the coating. Therefore, we hypothesize that the highest content of $\mathrm{OH}$-free groups in the PEC1 H3 1:2 coating and its higher flexibility compared to PEC1 H3 1:3 may be responsible for possible the self-healing properties. On the other hand, PEC1 H3 1:3 coating has higher amount of $\mathrm{N}-\mathrm{CO}$ groups in its formulation that decreases the amount of $\mathrm{OH}$-free groups and increases the rigidity making 

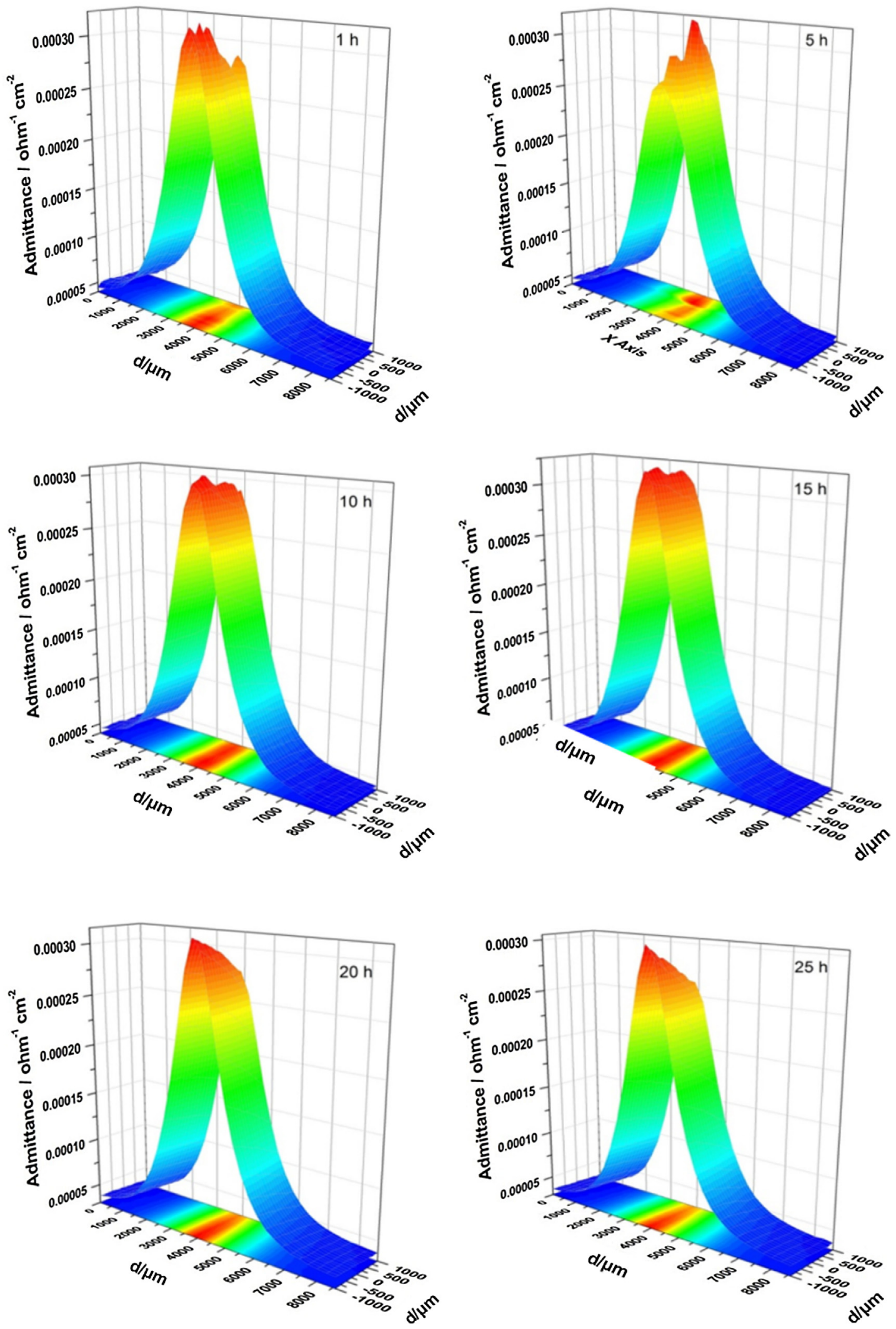

Fig. 11. LEIS map of the aluminum alloy coated with PEC1 H3 1:3 on both non-scratched and scratched areas in aerated $0.005 \mathrm{moll}^{-1} \mathrm{NaCl}$ solution at different immersion times.

more difficult the hydrogen-bonding formation, and therefore, no self-healing property was shown.
3.2.2. LEIS study

3.2.2.1. PEC1 H3 1:2 coating. Fig. 8 shows scratched PEC1 H3 1:2 coating surfaces before and after LEIS measurements in aerated 
$0.005 \mathrm{~mol} \mathrm{l}^{-1} \mathrm{NaCl}$ solution for $25 \mathrm{~h}$. Y and $\mathrm{X}$ values delimit the studied region and can vary from one to another sample, but cover both non-scratched and scratched areas of the coating.

Fig. 9 depicts the admittance mode of tridimensional LEIS maps of PEC1 H3 1:2 coating obtained in chloride solution at different times of immersion up to $25 \mathrm{~h}$.

The admittance outside the scratched area was low indicating a high impedance of the coating and thus good protective properties. The maximum of admittance was observed on the scratched area and its value decreased with the immersion time, indicating that the substrate became protected, probably due to coating recovery as confirmed by SEM imaging (Fig. 8D). This effect is responsible for the reduction of the corrosion activity of the substrate in the present conditions. This result agrees quite well with the localized SVET measurements and confirms the self-healing property of this coating.

\subsubsection{PEC1 H3 1:3 coating. Fig. 10 shows coating similar pictures} for PEC1 H3 1:3.

As for PEC1 H3 1:2 corrosion activity was only observed at the scratch but no relevant delamination could be measured.

In Fig. 11 the admittance of PEC1 H3 1:3 coating is higher in the scratch and very low outside. The values were nearly constant with the immersion time, revealing that the corrosion process was not hindered and that the coating was not recovered.

The results indicated that both localized techniques provide complementary information. SVET evidenced that PEC1 H3 1:2 is a coating able to repair over the defected areas and LEIS showed an increase of the local impedance with immersion time. On the other hand, LEIS showed that PEC1 H3 1:3 keeps almost constant admittance values, i.e., corrosion proceeded, and SVET provided additional information, and due to its better spatial resolution detected filiform corrosion, showing that corrosion occurred underneath the coating and that this coating was less protective.

\section{Conclusions}

Organic polymeric coatings prepared from crambe oil modified with trimethylolpropane (TMP) and phthalic anhydride (PhA), and hexamethylene diisocyanate in oxygenated organic solvents (H3) applied on ASTM $1200 \mathrm{H} 14$ aluminum alloy in the proportions 1:2 and $1: 3$ of PEC1 and $\mathrm{H} 3$ and studied in $\mathrm{NaCl}$ solution by open circuit measurements, and by SVET ( $24 \mathrm{~h}$ ) and LEIS ( $25 \mathrm{~h}$ ) inside and outside a scratch.

The thickness values revealed that PEC1 H3 1:3 is almost a half thickness of PEC1 H3 1:2 coating, suggesting a more rigid and compact structure.

For long immersion times and in non-scratched coatings, PEC1 H3 1:3 showed better performance than PEC1 H3 1:2, while in the presence of an artificial scratch the PEC1 H3 1:2 coating showed better performance compared to PEC1 $\mathrm{H} 31: 3$, as observed by the SVET analysis. This analysis has also indicated that PEC1 H3 1:2 coating recovered on the artificially-generated scratch, while the PEC1 H3 1:3 coating showed filiform corrosion for immersion times above $12 \mathrm{~h}$.

The PEC1 H3 1:2 coating showed decreasing admittance values with immersion time in $\mathrm{NaCl}$ medium, but with higher admittance values, suggesting coating recovering. The admittance values for PEC1 H3 1:3 coating were almost constant during the time course of experiment and the corrosion over the scratched area was not hindered.

SVET and LEIS provide complementary information that evidenced the differences in the corrosion process related to the coating composition.
These natural-derived organic coatings are potential materials for protecting aluminum alloys against corrosion in chloride solutions besides to be basically produced from vegetal oils, a renewable raw material.

\section{Acknowledgements}

AVB author gratefully acknowledge the Brazilian research agency CNPq (Proc. $n^{\circ}$ 305890/2010-7) for scholarship and grant, and JVN author thanks the São Paulo state agency FAPESP (Procs. 2012/22431-0 and 2013/23060-9) for scholarships. M.F. Montemor acknowledges Fundação para a Ciência e Tecnologia (FCT) for the funding under the contract UID/QUI/00100/2013. D. Snihirova acknowledges Fundação para a Ciência e Tecnologia (FCT) for her PhD grant SFR/BD/72497/2010.

\section{Appendix A. Supplementary data}

Supplementary data associated with this article can be found, in the online version, at http://dx.doi.org/10.1016/j.corsci.2016.05 034.

\section{References}

[1] M. Yan, V.J. Gelling, B.R. Hinderliter, D. Battocchi, D.E. Tallman, G.P. Bierwagen, SVET method for characterizing anti-corrosion performance of metal-rich coatings, Corros. Sci. 52 (2010) 2636-2642, http://dx.doi.org/10. 1016/j.corsci.2010.04.012.

[2] R.S. Lillard, P.J. Moran, H.S. Isaacs, A novel method for generating quantitative local electrochemical impedance spectroscopy, J. Electrochem. Soc. 139 (1992) 1007-1012, http://dx.doi.org/10.1149/1.2069332.

[3] F. Zou, D. Thierry, H.S. Isaacs, A high-resolution probe for localized electrochemical impedance spectroscopy measurements, J. Electrochem. Soc. 144 (1997) 1957-1965, http://dx.doi.org/10.1149/1.1837729.

[4] D.A. Worsley, H.N. McMurray, A. Belghazi, Determination of localised corrosion mechanisms using a scanning vibrating reference electrode technique, Chem. Commun. (1997) 2369-2370, http://dx.doi.org/10.1039/ a704530a.

[5] F.J. Maile, T. Schauer, C.D. Eisenbach, Evaluation of the delamination of coatings with scanning reference electrode technique, Prog. Org. Coat. 38 (2000) 117-120, http://dx.doi.org/10.1016/S0300-9440(00)00081-3.

[6] R.M. Souto, Y.G. García, J. Izquierdo, S. González, Examination of organic coatings on metallic substrates by scanning electrochemical microscopy in feedback mode: revealing the early stages of coating breakdown in corrosive environments, Corros. Sci. 52 (2010) 748-753, http://dx.doi.org/10.1016/j. corsci.2009.10.035.

[7] R.M. Souto, Y.G. García, S. González, Characterization of coating systems by Scanning Electrochemical Microscopy: surface topology and blistering, Prog. Org. Coat. 65 (2009) 435-439, http://dx.doi.org/10.1016/j.porgcoat.2009.03. 008 .

[8] I.D. Graeve, I. Schoukens, A. Lanzutti, F. Andreatta, A.A. Pampliega, J.D. Strycker, L. Fedrizzi, H. Terryn, Mechanism of corrosion protection of hot-dip aluminium-silicon coatings on steel studied by electrochemical depth profiling, Corros. Sci. 76 (2013) 325-336, http://dx.doi.org/10.1016/j.corsci. 2013.07.005

[9] D.V. Snihirova, L. Liphardt, G. Grundmeier, M.F. Montemor, Electrochemical study of the corrosion inhibition ability ofsmartcoatings applied on AA2024, J. Solid State Electrochem. 17 (2013) 2183-2192, http://dx.doi.org/10.1007/ s10008-013-2078-3.

[10] D.V. Snihirova, S.V. Lamaka, M.M. Cardoso, J.A.D. Condeço, H.E.C.S. Ferreira, M.F. Montemor, $\mathrm{pH}$-sensitive polymeric particles with increased inhibitor-loading capacity as smart additives for corrosion protective coatings for AA2024, Electrochim. Acta 145 (2014) 123-131, http://dx.doi.org/10. 1016/j.electacta.2014.09.009.

[11] D.V. Snihirova, S.V. Lamaka, M.F. Montemor, SMART protective ability of water based epoxy coatings loaded with $\mathrm{CaCO}_{3}$ microbeads impregnated with corrosion inhibitors applied on AA2024 substrates, Electrochim. Acta 83 (2012) 439-447, http://dx.doi.org/10.1016/j.electacta.2012.07.102.

[12] F. Zou, D. Thierry, Localized electrochemical impedance spectroscopy for studying the degradation of organic coatings, Electrochim. Acta 42 (1997) 3293-3301, http://dx.doi.org/10.1016/S0013-4686(97)00180-1.

[13] D.V. Snihirova, S.V. Lamaka, P. Taheri, J.M.C. Mol, M.F. Montemor, Comparison of the synergistic effects of inhibitor mixtures tailored for enhanced corrosion protection of bare and coated AA2024-T3, Surf. Coat. Technol. 2 (2015) 1-10, http://dx.doi.org/10.1016/j.surfcoat.2015.10.075 (Available online 2 November)

[14] M. Mouanga, F. Andreatta, M.E. Druart, E. Marin, L. Fedrizzi, M.N.G. Olivier, A localized approach to study the effect of cerium salts as cathodic inhibitor on 
iron/aluminum galvanic coupling, Corros. Sci. 90 (2015) 491-502, http://dx. doi.org/10.1016/j.corsci.2014.03.026.

[15] M.W. Wittmann, R.B. Leggat, S.R. Taylor, The detection and mapping of defects in organic coatings using local electrochemical impedance methods, J. Electrochem. Soc. 146 (1999) 4071-4075, http://dx.doi.org/10.1149/1. 1392593.

[16] L.V.S. Philippe, G.W. Walter, S.B. Lyon, Investigating localized degradation of organic coatings: comparison of electrochemical impedance spectroscopy with Local Electrochemical Impedance Spectroscopy, J. Electrochem. Soc. 150 (2003) Blll-B119, http://dx.doi.org/10.1149/1.1554913.

[17] M.F. Montemor, Functional and smart coatings for corrosion protection: a review of recent advances, Surf. Coat. Technol. 258 (2014) 17-37, http://dx. doi.org/10.1016/j.surfcoat.2014.06.031.

[18] J.V. Nardeli, C.S. Fugivara, A.V. Benedetti, Environmentally friendly coatings applied on aluminum alloy ASTM 1200, Santiago de Querétaro. Surface treatments. Switzerland:International Society of Electrochemistry, in: Annual Meeting Of The International Society Of Electrochemistry, 64th, 2013, vol. 1, 2013, p. 98.

[19] M.I. Aranguren, J.F. González, M.A. Mosiewicki, Biodegradation of a vegetable oil based polyurethane and wood flour composites, Polym. Test. 31 (2012) 7-15, http://dx.doi.org/10.1016/j.polymertesting.2011.09.001.

[20] R.V.V. Lopes, L.F.B. Osorio, M.L. Santos, M.J.A. Sales, Characterization of polyurethanes from vegetable oils by TG/DTG, DMA and FT-IR, Macromol. Symp. 319 (2012) 173-178, http://dx.doi.org/10.1002/masy.201100162.

[21] R.V.V. Lopes, N.P.D. Loureiro, A.P.T. Pezzin, A.C.M. Gomes, I.S. Resck, M.J.A Sales, Synthesis of polyols and polyurethanes from vegetable oils-kinetic and characterization, J. Polym. 238 (2013) 1-9, http://dx.doi.org/10.1007/s10965013-0238-X.

[22] B. Elsener, A. Rota, H. Bohni, Impedance study on the corrosion of PVD and CVD titanium nitride coatings, Mater. Sci. Forum 44-45 (1989) 29-38, http:// dx.doi.org/10.4028/www.scientific.net/MSF.44-45.29.

[23] M. Lakatos-Varsanyi, D. Hanzel, Cyclic voltammetry measurements of different single-, bi- and multilayer TiN and single layer $\mathrm{CrN}$ coatings on low-carbon-steel substrates, Corros. Sci. 41 (1999) 1585-1589, http://dx.doi. org/10.1016/S0010-938X(99)00004-9.

[24] J. Piippo, B. Elsener, H. Bohni, Impedance study on thin inorganic coatings, Mater. Sci. Forum 111-112 (1992) 219-230, http://dx.doi.org/10.4028/www scientific.net/MSF.111-112.219.

[25] P. Ernst, A. Earnshaw, I.P. Wadsworth, G.W. Marshall, Cementation as a method of observing defects in PVD coatings, Corros. Sci. 39 (1997) 1329-1334, http://dx.doi.org/10.1016/S0010-938X(97)00032-2.

[26] W. Tato, D. Landolt, Electrochemical determination of the porosity of single and duplex PVD coatings of titanium and titanium nitride on brass, J. Electrochem. Soc. 145 (1998) 4173-4181, http://dx.doi.org/10.1149/1. 1838932.

[27] P. Rodic, I. Milosev, Corrosion properties of UV cured hybrid sol-gel coatings on AA7075-T6 determined under simulated aircraft conditions, J. Electrochem. Soc. 161 (2014) C412-C420, http://dx.doi.org/10.1149/2. 1091409jes.

[28] I.M. Notter, D.R. Gabe, Porosity of electrodeposited coatings: its cause, nature, effect and management, Corros. Rev. 10 (1992) 217-280, http://dx.doi.org/10 1515/corrrev.1992.10.3-4.217.

[29] B. Matthes, E. Broszeit, J. Aromaa, H. Ronkainen, S.P. Hannula, A. Leyland, A Matthews, Corrosion performance of some titanium-based hard coatings, Surf. Coat. Technol. 49 (1991) 489-495, http://dx.doi.org/10.1016/02578972(91)90105-6.

[30] J. Creus, H. Idrissi, H. Mazille, Galvanic corrosion behaviour of mild steel, Al, and $\mathrm{Ti}$ in $3 \% \mathrm{NaCl}$ solution: application to PVD coatings on steel substrate, Surf. Eng. 13 (1997) 415-419.

[31] R.J. Morrissey, Electrolytic determination of porosity in gold electroplates, J. Electrochem. Soc. 117 (1970) 742-747, http://dx.doi.org/10.1149/1.2407621.

[32] J.R. Scully, S.T. Hensley, Lifetime prediction for organic coatings on steel and magnesium alloy using electrochemical impedance methods, Corros. Sci. 50 (1994) 705-716, http://dx.doi.org/10.5006/1.3293547.

[33] R. Hirayama, S. Haruyama, Electrochemical impedance for degraded coated steel having pores, Corros. Sci. 47 (1991) 952-958, http://dx.doi.org/10.5006 1.3585208.

[34] H.P. Hack, J.R. Scully, Defect area determination of organic coated steels in seawater using the breakpoint frequency method, J. Electrochem. Soc. 138 (1991) 33-40, http://dx.doi.org/10.1149/1.2085574.
[35] Z. Feng, G.S. Frankel, Evaluation of coated Al alloy using breakpoint frequency method, Electrochim. Acta 187 (2016) 605-615, http://dx.doi.org/10.1016/j. electa.2015.11.114.

[36] J.B. Jorcin, H. Krawiec, N. Pébère, V. Vignal, Comparison of local electrochemical impedance measurements derived from bi-electrode and microcapillary techniques, Electrochim. Acta 54 (2009) 5775-5781, http://dx. doi.org/10.1016/j.electacta.2009.05.029.

[37] C. Liu, Q. Bi, A. Leyland, A. Matthews, An electrochemical impedance spectroscopy study of the corrosion behaviour of PVD coated steels in $0.5 \mathrm{~N}$ $\mathrm{NaCl}$ aqueous solution: part II. EIS interpretation of corrosion behavior, Corros. Sci. 45 (2003) 1257-1273, http://dx.doi.org/10.1016/S0010938X(02)00213-5.

[38] S. Harwama, S. Sudo, Electrochemical impedance for a large structure in soil Electrochim. Acta 38 (1993) 1857-1865, http://dx.doi.org/10.1016/00134686(93)80307-L.

[39] D. Ramesh, T. Vasudevan, Evaluation of corrosion stability of water soluble epoxy-ester primer through electrochemical studies, Mater. Sci. Appl. 3 (2012) 333-347, http://dx.doi.org/10.4236/msa.2012.36049.

[40] Y. Huang, H. Shih, H. Huang, J. Daugherty, S. Wu, S. Ramanathan, C. Chang, F. Mansfeld, Evaluation of the corrosion resistance of anodized aluminum 6061 using electrochemical impedance spectroscopy (EIS), Corros. Sci. 50 (2008) 3569-3575, http://dx.doi.org/10.1016/j.corsci.2008.09.008.

[41] M. Mahdavian, M.M. Attar, Another approach in analysis of paint coatings with EIS measurement: phase angle at high frequencies, Corros. Sci. 48 (2006) 4152-4157, http://dx.doi.org/10.1016/j.corsci.2006.03.012.

[42] Y. Zuo, R. Pang, W. Li, J.P. Xiong, Y.M. Tang, The evaluation of coating performance by the variations of phase angles in middle and high frequency domains of EIS, Corros. Sci. 50 (2008) 3322-3328, http://dx.doi.org/10.1016/j. corsci.2008.08.049.

[43] M. Fedel, F. Deflorian, S. Rossi, Correlations between the volta potential and filiform corrosion on painted AA2024 aluminum alloy, Surf. Interface Anal. 42 (2010) 199-204, http://dx.doi.org/10.1002/sia.3141.

[44] G. Williams, H.N. McMurray, Inhibition of filiform corrosion on organic-coated AA2024-T3 by smart-release cation and anion-exchange pigments, Electrochim. Acta 69 (2012) 287-294, http://dx.doi.org/10.1016/j. electacta.2012.03.002.

[45] H.N. McMurray, A. Holder, G. Williams, G.M. Scamans, A.J. Coleman, The kinetics and mechanisms of filiform corrosion on aluminium alloy AA6111, Electrochim. Acta 55 (2010) 7843-7852, http://dx.doi.org/10.1016/j.electacta. 2010.04.035

[46] L. Fedrizzi, M. Stenico, F. Deflorian, S. Maschio, P.L. Bonora, Effect of powder painting procedures on the filiform corrosion of aluminium profiles, Prog. Org. Coat. 59 (2007) 230-238, http://dx.doi.org/10.1016/j.porgcoat.2006.02.011.

[47] M.G. Olivier, M. Poelman, M. Demuynck, J.P. Petitjean, EIS evaluation of the filiform corrosion of aluminium coated by a cataphoretic paint, Prog. Org. Coat. 52 (2005) 263-270, http://dx.doi.org/10.1016/j.porgcoat.2004.05.008.

[48] X.F. Liu, Filiform corrosion attack on pretreated aluminum alloy with tailored surface of epoxy coating, Corros. Sci. 49 (2007) 3494-3513, http://dx.doi.org/ 10.1016/j.corsci.2007.03.031.

[49] G. Williams, H.N. McMurray, Polyaniline inhibition of filiform corrosion on organic coated AA2024-T3, Electrochim. Acta 54 (2009) 4245-4252, http://dx. doi.org/10.1016/j.electacta.2009.02.077.

[50] K.A. Yasakau, M.L. Zheludkevich, S.V. Lamaka, M.G.S. Ferreira, Mechanism of corrosion inhibition of AA2024 by rare-earth compounds, J. Phys. Chem. 110 (2006) 5515-5528, http://dx.doi.org/10.1021/jp0560664.

[51] R.S. Mishra, A.S. Khanna, Formulation and performance evaluation of hydroxyl terminated hyperbranched polyesters based poly (ester-urethane-urea) coatings on mild steel, Prog. Org. Coat. 72 (2011) 769-777, http://dx.doi.org/10.1016/j.porgcoat.2011.08.009.

[52] D.B. Otts, M.W. Urban, Heterogeneous crosslinking of waterborne two-component polyurethanes (WB 2K-PUR); stratification processes and the role of water, Polymer 46 (2005) 2699-2709, http://dx.doi.org/10.1016/j. polymer.2005.01.053.

[53] M. Huang, J. Yang, Facile microencapsulation of HDI for self-healing anticorrosion coatings, J. Mater. Chem. 21 (2011) 11123-11130, http://dx.doi. org/10.1039/c1jm10794a.

[54] Z.S. Petrovic, Polyurethanes from vegetable oils, Polym. Rev. 48 (2008) 109-155, http://dx.doi.org/10.1080/15583720701834224. 